\title{
A preliminary study of the nonlinearity of adhesive point-fixings in structural glass facades
}

\author{
Jonas Dispersyn ${ }^{\mathrm{a}, *}$, Manuel Santarsiero ${ }^{\mathrm{b}}$, Jan Belis ${ }^{\mathrm{a}}$ and Christian Louter ${ }^{\mathrm{b}}$ \\ a Laboratory for Research on Structural Models (LMO), Department of Structural Engineering, Faculty \\ of Engineering and Architecture, Ghent University, Ghent, Belgium \\ ${ }^{b}$ Steel Structures Laboratory (ICOM), School of Architecture, Civil and Environmental Engineering \\ (ENAC), École Polytechnique Fédérale de Lausanne (EPFL), Lausanne, Switzerland
}

Submitted 19 September 2014

Revised 29 October 2014

Accepted 14 November 2014

\section{Abstract.}

The recent demand for architectural transparency has drastically increased the use of glass material for structural purpose. However, connections between structural glass members represent one of the most critical aspects of glass engineering, due to the fragile behaviour of this material. In that respect, research activities on adhesive point-fixings are currently on-going. The mechanical behaviour of adhesive point-fixings is affected by large nonlinearities, which are usually investigated by nonlinear Finite Element Analysis (FEA). This paper focuses on the geometrical and the material nonlinearities of adhesive point-fixings for glass structures.

Firstly, the nonlinear material behaviour of two selected adhesives are investigated by means of uniaxial tension and compression tests on the bulk material. The production of specimens, test methodology and displacement rate dependency are discussed. Secondly, the nonlinear stress distribution occurring in the adhesive and the joint stiffness is investigated by means of nonlinear FEA. The effects of several parameters on the mechanical behaviour of adhesive point-fixings, such as the connection dimensions and adhesive elastic properties, are studied.

The adhesive stress-strain curves resulting from the experimental campaign show that the adhesives exhibit a large nonlinear behaviour. The results show that the stress and strain at failure reduce as the displacement rate is reduced. From the numerical investigations it is concluded that large nonlinearity involves the mechanical behaviour of adhesive point-fixing which cannot be neglected. The stress distribution within the adhesive deviates from uniform nominal stresses, even in case of simple load condition, with stress peaks up to four times higher than nominal stresses.

Keywords: Structural analysis, glass facades, glass, steel, numerical model

\section{List of notation}
$\alpha_{\sigma, \max } \quad[-]$ ratio between the maximum principal stress and the nominal stress
$\alpha_{\sigma, \text { mis }} \quad[-]$ ratio between the Von Mises stress and the nominal stress
$\sigma_{\text {nom }} \quad[\mathrm{MPa}]$ nominal stress

\footnotetext{
*Corresponding author: Jonas Dispersyn, Laboratory for Research on Structural Models (LMO), Department of Structural Engineering, Faculty of Engineering and Architecture, Ghent University, Ghent, Belgium. Tel.: +32 926454 84; Fax: +32 9 26458 38; E-mail: jonas.dispersyn@UGent.be.
}

ISSN 2214-302X/14/\$35.00 @ 2014 - IOS Press and the authors. All rights reserved

This article is published online with Open Access and distributed under the terms of the Creative Commons Attribution Non-Commercial License. 


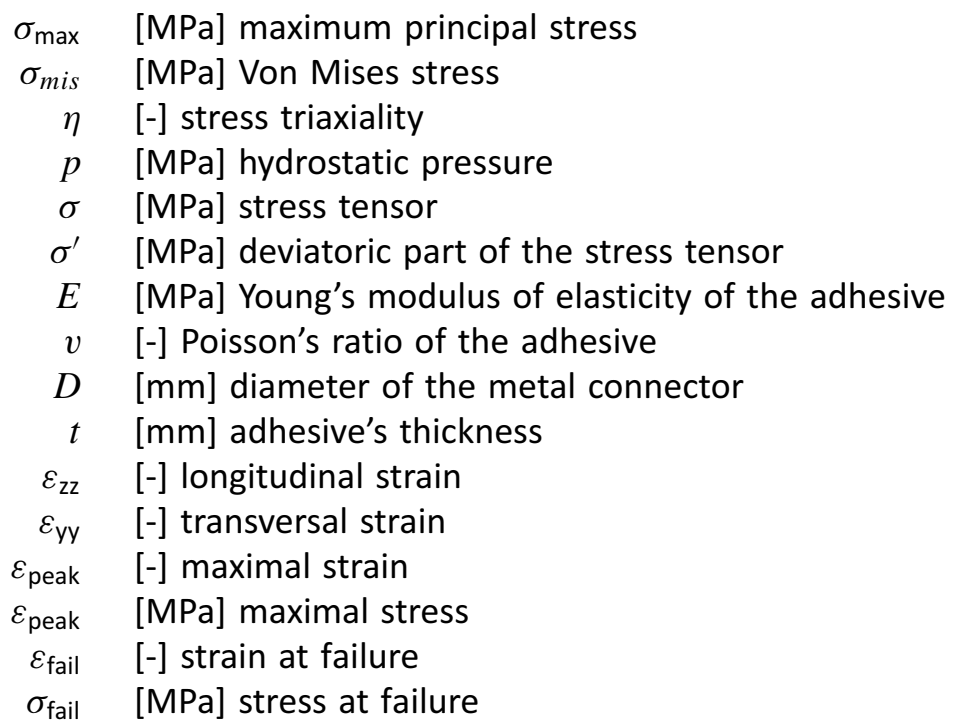

\section{Introduction}

The demand for architectural transparency has drastically increased the use of glass as a structural material. However, connections between structural glass members still represent one of the most critical aspects of glass engineering because of the fragile behaviour of the material. Traditional systems to connect glass to the supporting substructure consist of linear supports, schematically depicted in Fig. 1a. By using such systems, the transparency of the facade is highly reduced (Haldimann et al., 2008). In contrast, the overall transparency improves significantly by using so-called point-fixings (Siebert \& Herrmann, 2010; Vyzantiadou \& Avdelas, 2004). These fixings typically consist of locally installed metal, of limited size, connecting the glass elements to the structure using bolts through the glass. This requires the glass panel to be drilled near the corners or edges, and subsequently to be tempered and bolted (Siebert, 2006), as depicted in Fig. 1b and c. A recent technology prevents drilling through the glass by using so-called undercut point-fixings, as illustrated in Fig. 1d. These connections do not penetrate the insulation cavity at insulating glass units.

However, with bolted connections, the glass is significantly weakened by the drilling process at the holes edges, which is where high stress peaks occur due to the local transfer of forces by the glass (Beyer, 2007; Feldmann et al., 2008; Maniatis, 2006; Mocibob \& Belis, 2010; Overend 2005). The use of adhesive connections avoids this issue because the glass is directly bonded to the metal connector (see Figs. 1e and 2). Indeed, adhesive joints reduce high stress peaks by spreading the force over a larger area (Dispersyn et al., 2014; Overend et al., 2012; Santarsiero et al., 2013; Sitte et al., 2011; Weller \& Tasche, 2005). The risk of thermal bridges and condensation is also strongly reduced.

Analytical prediction of the mechanical behaviour of adhesive point-fixings is rather complex and no analytical models are currently available. The structural response and stress distribution are indeed affected by severe nonlinearities. Because of that, adhesive point-fixings are usually designed by means of nonlinear Finite Element Analyses (FEA). This work presents the results of two separated research activities performed at Ghent University (Belgium) and at EPFL (Switzerland), which focus on different aspects of the nonlinear behaviour of adhesive point-fixings. 

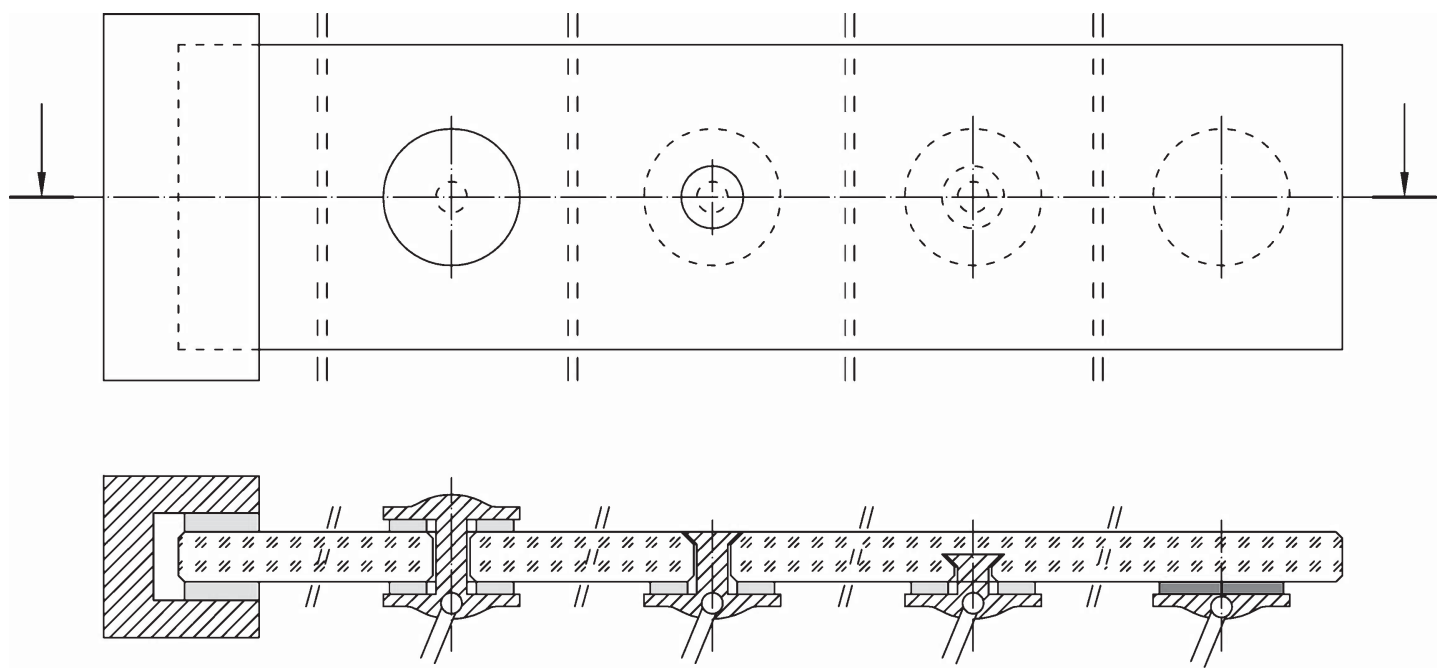

a)

b)

c)

d)

e)

Fig. 1. Schematic representation (cross-section) of three different ways to attached glass panels to the underlying structure with a) linear supports, b), c) and d) bolted point-fixings and e) adhesive point-fixings.
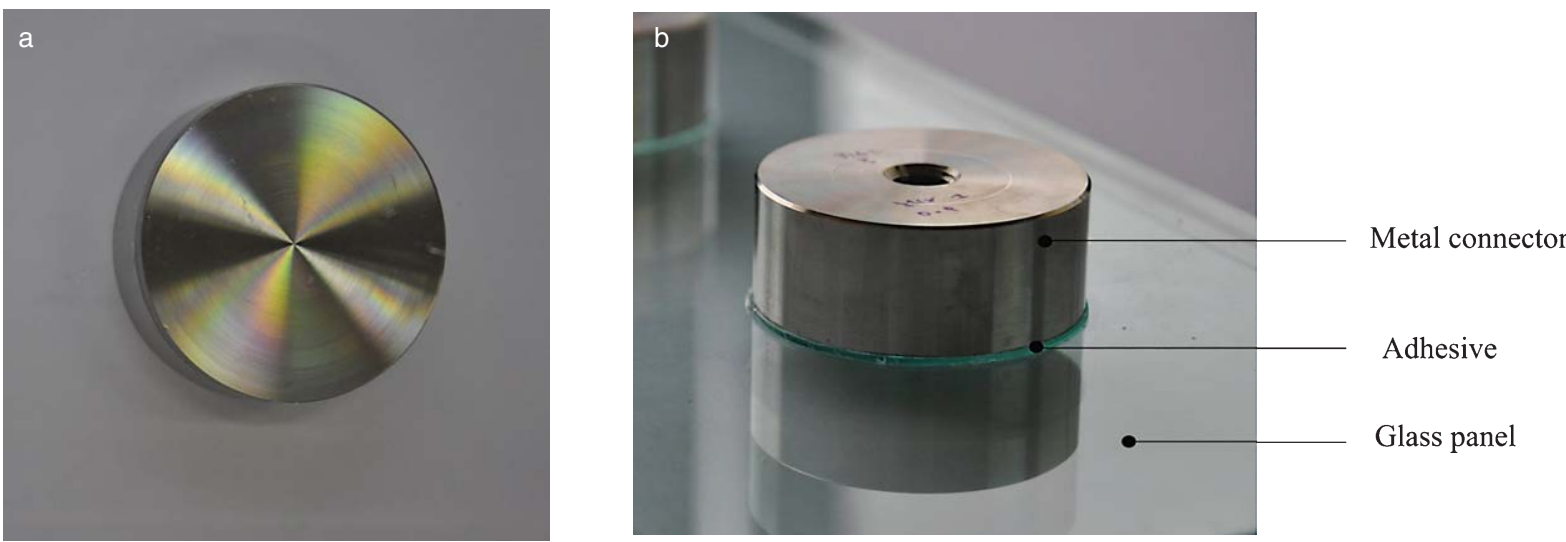

Fig. 2. Transparent adhesive connection.

Adhesive material shows large nonlinearity in the stress-strain constitutive law. The stress-strain constitutive law of adhesive materials is usually obtained by experimental tests on the bulk adhesive material. The fabrication of specimens is thereby critical. The first part of the paper focuses on the nonlinearity of the adhesive material under uniaxial tensile and compressive forces. The experimental investigations of two selected adhesives (i.e. a soft MS-polymer and a stiffer two-component epoxy) are presented. The fabrication of the specimens, testing methodology and results are discussed.

To determine the maximum stress that the adhesive can withstand, experimental investigations are performed measuring the load at failure. However, the stress distribution within the adhesive is strongly nonlinear, even in case of linear material and simple load conditions such as pure tensile and pure shear load. The maximum stress peak in the adhesive at failure is larger than the nominal stress (i.e. force divided by adhesive area). This is mainly due to the confined stress state of the adhesive 
caused by the large ratio between diameter and adhesive thickness. Accurate FEA are therefore necessary to correlate the maximum force measured during the test to the maximum adhesive stress. The second part of this work presents a parametrical study on the effects of mechanical and geometrical parameters on the stress distribution in the adhesive and on the joint stiffness. In this part the adhesive material is assumed to be linear elastic, to investigate confinement effect nonlinearity separately from the material nonlinearity.

\section{Material nonlinearity}

This first section focuses on the material nonlinearity of adhesive materials for point-fixings. The hypothesis of linear elastic material is often not accurate enough for polymeric adhesive material used in point-fixing connections. These materials are indeed characterized by stress-strain constitutive laws that yield large nonlinear behaviour that need to be accounted for in the numerical simulation.

To obtain an accurate stress distribution in the adhesive under large deformations, the nonlinear mechanical behaviour of the adhesive should be taken into consideration. This is done by implementing stress-strain curves in the FEA. These stress-strain curves are usually obtained by uniaxial tensile tests and compression tests on bulk material of the adhesive (Overend et al., 2011; Santarsiero \& Louter, 2014). Adhesive point-fixings will mainly be loaded in pressure or tensile by pressure of suction of wind load. For this reason only tensile is considered in this article. Dead load of glass panel will be carried by mechanical self-weight support as it is usually done for Structural Sealant Glazing Systems, as described by ETAG 002 (ETAG 002).

\subsection{Materials and method}

\subsubsection{Selection of the adhesives}

There are many types of adhesives on the market varying from relatively flexible and low-strength adhesives, such as silicones, to relatively stiff and high-strength adhesives, such as epoxies and acrylates. The latter are non-toughened, thermosetting adhesives. These kinds of adhesives are usually brittle materials that will fail at relatively small strains. These materials mostly yield sufficient accuracy when modelled with linear elastic behaviour, as long as the deformations and temperature are not too high. In contrast, other commercial adhesives are rubber toughened, such as silicones and MS-polymers. Due to the rubber phase that occurs here, relatively large strains ( $>5 \%$ ) can occur with large deformation prior to failure. Two adhesives are selected, namely one relatively flexible and low-strength adhesive and one relatively stiff and high-strength adhesive.

The selection is made based on earlier research. An extensive experimental programme on adhesives for structural applications with glass and metal connectors has been performed by researchers of Ghent University and Delft University of Technology to help designers select potential adhesives based on specific environmental exposures and loading conditions. The project yielded an adhesive selection tool based on performance criteria (Belis et al., 2011a, b).

The selected adhesives are:

- Soudaseal 270 HS, a MS-polymer (Modified Silane) adhesive, a hybrid polymer adhesive with a base of polyurethane and silicone. This adhesive combines the advantages of a polyurethane adhesive and a silicone, which gives a strong and flexible bond. 
- 3M Scotch Weld 9323 B/A: this two-component epoxy adhesive presented good properties on both tensile and shear strength.

\subsubsection{Tensile test samples}

Young's modulus and Poisson's ratio can be obtained by small-scale tests, commonly by means of uniaxial tensile tests on dumbbell specimens. The outcome of these small-scale tests can also be used to determine the nonlinear behaviour of the adhesive.

In principle dumbbell specimens of adhesive products can be fabricated with a mould or with cutting dies. With the former method, the adhesive is poured and cured in a mould. To avoid bonding to the mould, the latter should be manufactured out of material with a low solid surface free energy. With the latter method, a layer of adhesive has to be made with a thickness of several millimetres. After curing, the dumbbell specimens can then be punched out of the film with a cutting device. However, this technique results in relatively quantities of waste material. In addition, it is problematic to make a layer with a continuous thickness. Consequently, it is decided to work with a mould for the current study.

The adhesive dumbbell specimens are fabricated at the University of Luxembourg, by means of a non-sticky mould (Dias et al., 2012), following the geometry provided in ISO 527-2, see Fig. 3 (ISO 572-2). By means of the mould three samples were fabricated at the same time, as depicted in Fig. 4. The mould is fabricated from Polyoxymethylene (POM), a stiff material with a low solid surface free energy. After curing, the samples are stored at a constant temperature of $21^{\circ} \mathrm{C}$ and a relative humidity of $45 \%$ without any UV-radiation in a climatic chamber.

The curing process of the MS-polymer Soudaseal 270 HS is moisture curing. Since the chosen fabrication method implied sealing off the sample from air, extra water was mixed with the adhesive before injecting it into the mould to increase its moisture content. After contacting the manufacturer

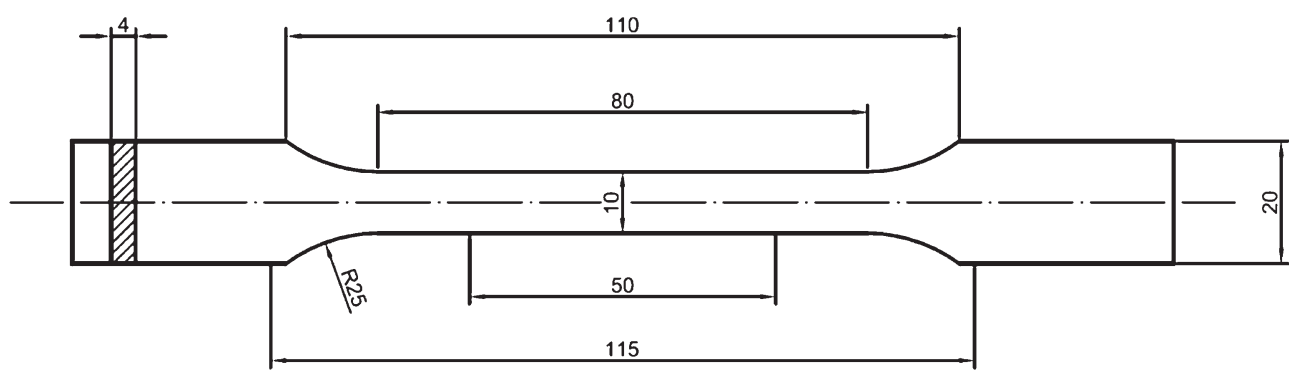

Fig. 3. Dimensions according to ISO 572-2 (ISO 572-2).

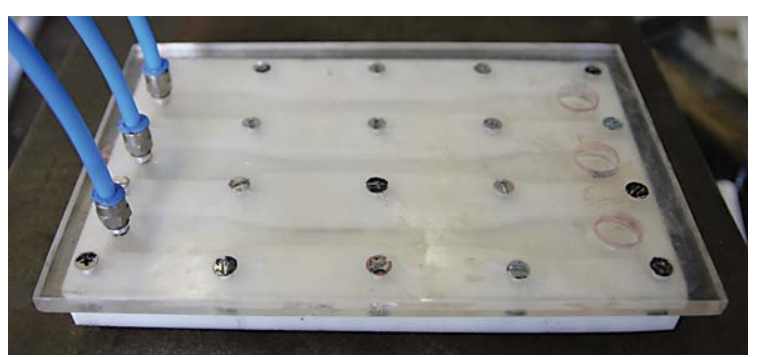

Fig. 4. Mould for uniaxial tensile samples according to ISO 572-2 type 1B. 


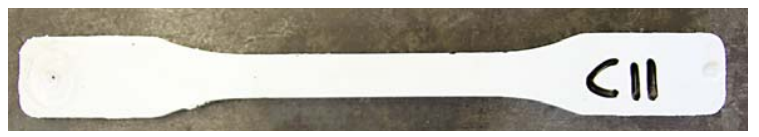

Fig. 5. Dumbbell sample of the MS-polymer Soudaseal 270 HS.

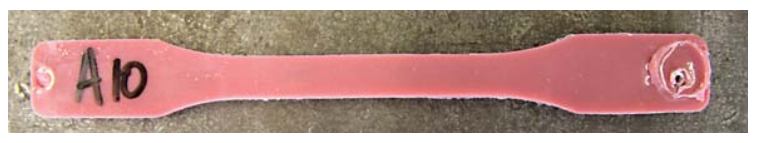

Fig. 6. Dumbbell sample of the epoxy 3M Scotch Weld $9323 \mathrm{~B} / \mathrm{A}$.

of Soudaseal $270 \mathrm{HS}$, this extra amount of humidity was set to $5 \%$. The polymer was sucked in the mould by using the vacuum pump to avoid air bubbles in the samples. An example of a dumbbell sample of the MS-polymer Soudaseal 270 HS is given in Fig. 5. In total 18 samples were fabricated.

The mixing ratios by weight of the two components of the epoxy 3M Scotch Weld $9323 \mathrm{~B} / \mathrm{A}$ are 27 to 100 , respectively. The weighing of each component is done with a balance having an accuracy of 0.1 gram. The components are mixed manually in a specific Teflon cartridge, which is then installed on the mould. However, the vacuum pump could not be used due to the low viscosity of the mixed adhesive. Consequently it was pushed manually in the mould by means of a self-designed injector. The curing of the adhesive took place inside the mould. Due to the high adhesion of the epoxy, an extra thin sheet of transparent PE film of 0.1 thickness was placed between the adhesive and the Plexiglas ${ }^{\circledR}$ cover of the mould. An example of a dumbbell sample of the epoxy 3M Scotch Weld 9323 B/A is given in Fig. 6 . In total 22 samples were fabricated for testing.

\subsubsection{Compressive test samples}

In realistic situations the adhesive in an adhesive joint is mostly not only loaded in tension. Complex stress distributions occur when the adhesive is loaded in several types of loading. Hence, to take the compressive mode into account compressive tests are indispensable. Compressive tests on bulk material are not as commonly executed as tensile tests, but the FEA will be more accurate if experimental data is obtained for different load directions. With compressive tests on bulk material attention has to be paid to the compressive plates. The latter have to be parallel to each other and to avoid friction between the samples and the plates, lubricant or Teflon plates can be used. The test samples can be typical blocks or cylinders (ISO 604, ASTM D695). In this research the cylindrical compressive specimens are produced in a PTFE-mould with a diameter of $30 \mathrm{~mm}$ and a height of $15 \mathrm{~mm}$, as depicted in Fig. 7.

During the removal from the mould, the upper surface of the epoxy samples was damaged. Therefore, a $5 \mathrm{~mm}$ layer was removed from the top of the samples, resulting in a height of $10 \mathrm{~mm}$. An example of a Soudaseal 270 HS compression sample is given in Fig. 8a and of Scotch Weld 9323 B/A in $8 \mathrm{~b}$. In total eight samples of each adhesive were selected for testing. After fabrication, the samples were also stored at a temperature of $21^{\circ} \mathrm{C}$ and a relative humidity of $45 \%$ without UV-radiation.

\subsubsection{Tensile tests}

The tensile tests were performed on a universal electro-mechanic test machine Instron $5800 \mathrm{R}$ (frame 4505 retrofitted with a digital controller 8800 ). A load cell of $10 \mathrm{kN}$ was used for the test results 


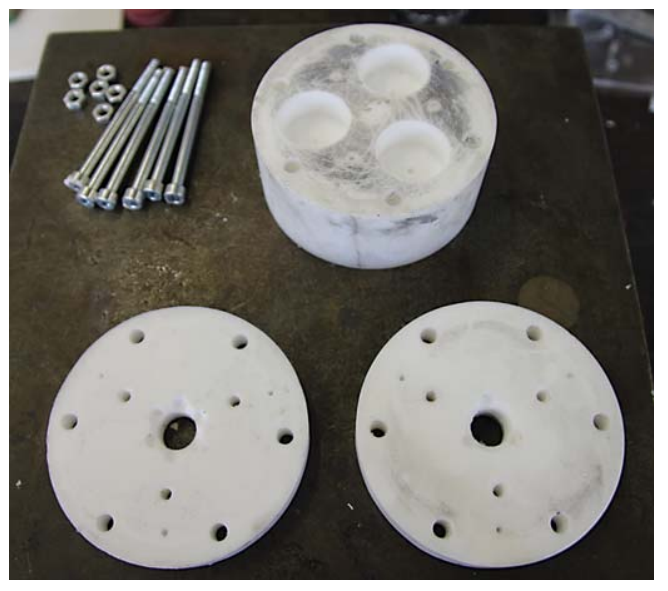

Fig. 7. Mould for uniaxial compression samples.
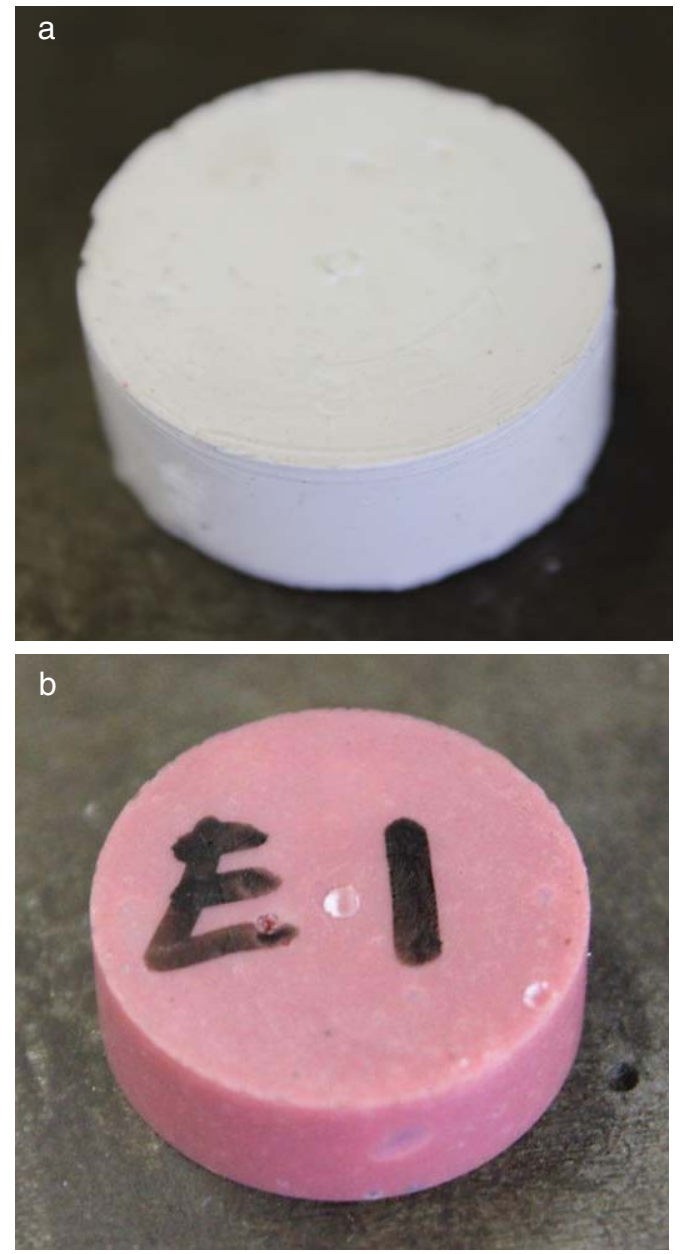

Fig. 8. Compression sample of a) Soudaseal $270 \mathrm{HS}$ and b) Scotch Weld 9323 B/A. 
Table 1

Theoretical tensile displacement rates and strain rates, calculated based on technical datasheets, for chosen time to failure

\begin{tabular}{lcccccc}
\hline Time till failure & \multicolumn{2}{c}{ Soudaseal $270 \mathrm{HS}$} & & \multicolumn{2}{c}{ Scotch Weld $9323 \mathrm{~B} / \mathrm{A}$} \\
\cline { 2 - 3 } \cline { 6 - 7 } & $\begin{array}{c}\text { Displacement } \\
\text { rate }[\mathrm{mm} / \mathrm{min}]\end{array}$ & $\begin{array}{c}\text { Strain rate } \\
{[-/ \mathrm{min}]}\end{array}$ & & $\begin{array}{c}\text { Displacement } \\
\text { rate }[\mathrm{mm} / \mathrm{min}]\end{array}$ & $\begin{array}{c}\text { Strain rate } \\
{\left[10^{-3} / \mathrm{min}\right]}\end{array}$ \\
\hline $20 \mathrm{sec}$. & $253^{*}$ & 4.22 & & 6 & 100 \\
$2 \mathrm{~min}$. & 75 & 1.25 & & 1 & 16.67 \\
$10 \mathrm{~min}$. & 15 & 0.25 & & 0.2 & 3.33 \\
\hline
\end{tabular}

*Theoretical value is $450 \mathrm{~mm} / \mathrm{min}$, but $253 \mathrm{~mm} / \mathrm{min}$ was the maximum speed of the tensile testing machine.

presented in this paper. The load and the displacement between the clamping devices were measured with respectively an accuracy of $\pm 0.023 \mathrm{kN}$ and $\pm 0.02 \mathrm{~mm}$ and registered at a frequency of $10 \mathrm{~Hz}$ until failure of the dumbbell sample occurred. The tests were performed at ambient temperature, i.e. $18.5^{\circ} \mathrm{C}$. A constant displacement rate $v$ was applied on the mobile clamp, and this was comprised between 2 and $60 \mathrm{~mm} / \mathrm{min}$ according to the test.

Because of the viscoelastic behaviour of adhesives, it is also important to determine the ratedependency. This is done by performing the uniaxial tensile tests with three different displacement rates. The loading rate of each adhesive was established depending on the elongation at break. With the maximum deformation given in the technical datasheets of the adhesive and in the earlier research, the theoretical displacement rates can be calculated. Due to time constraints, the three different time intervals to failure are set at 20 seconds, 2 minutes and 10 minutes. The applied displacement rates are summarized in Table 1 . Since the maximum deformations given by the adhesives manufacturers are lower limits (characteristic values), the expected experimental time to failure is longer than calculated.

\subsubsection{Compressive test}

The compressive tests were performed on the same machine. The samples are placed between two parallel steel plates, as illustrated in Fig. 9. Minimal friction between the plates and the sample was obtained by spraying PTFE-spray on the plates. The load and the displacement between the plates are measured and registered at a frequency of $10 \mathrm{~Hz}$ till $10 \mathrm{kN}$ was reached.

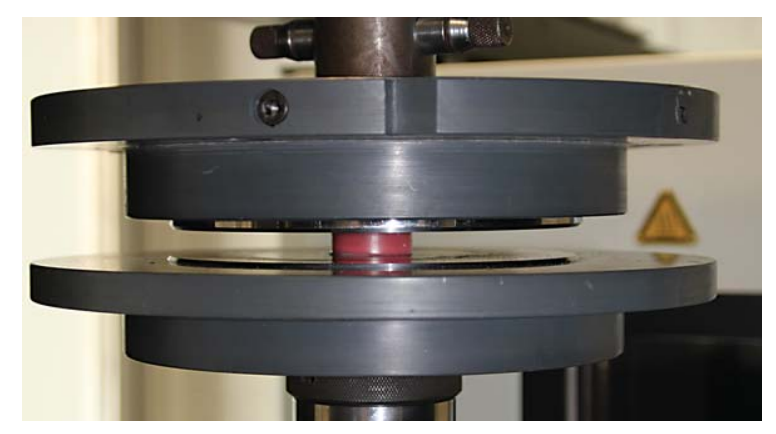

Fig. 9. Compressive test on Scotch Weld $9323 \mathrm{~B} / \mathrm{A}$. 
Table 2

Theoretical compression displacement rates and strain rates, calculated based on technical datasheets, for chosen time to failure

\begin{tabular}{lccccr}
\hline Time till failure & \multicolumn{2}{c}{ Soudaseal 270 HS } & & \multicolumn{2}{c}{ Scotch Weld 9323 B/A } \\
\cline { 2 - 3 } & $\begin{array}{c}\text { Displacement } \\
\text { rate }[\mathrm{mm} / \mathrm{min}]\end{array}$ & $\begin{array}{c}\text { Strain rate } \\
{[-/ \mathrm{min}]}\end{array}$ & & $\begin{array}{c}\text { Displacement } \\
\text { rate }[\mathrm{mm} / \mathrm{min}]\end{array}$ & $\begin{array}{r}\text { Strain rate } \\
{\left[10^{-3} / \mathrm{min}\right]}\end{array}$ \\
\hline 2 min. & 5 & 0.333 & 0.2 & 20 \\
10 min. & 1 & 0.067 & 0.04 & 4 \\
\hline
\end{tabular}

a) MS-polymer

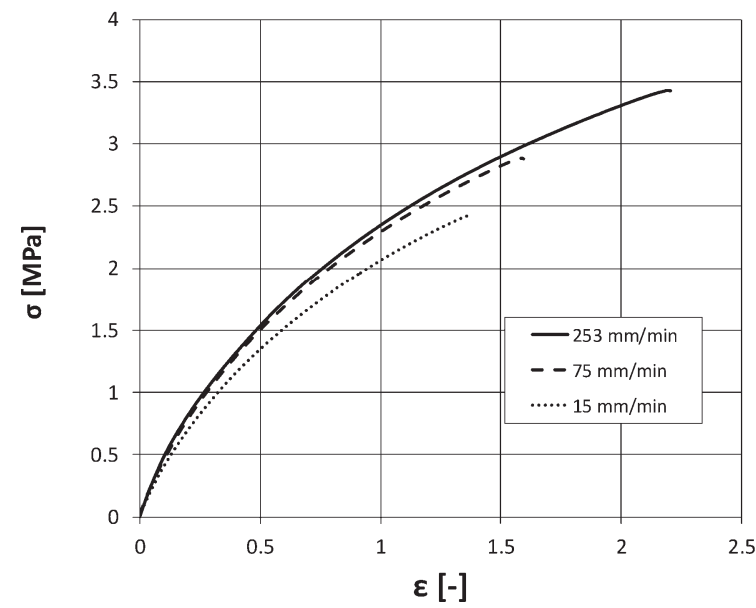

b) Epoxy

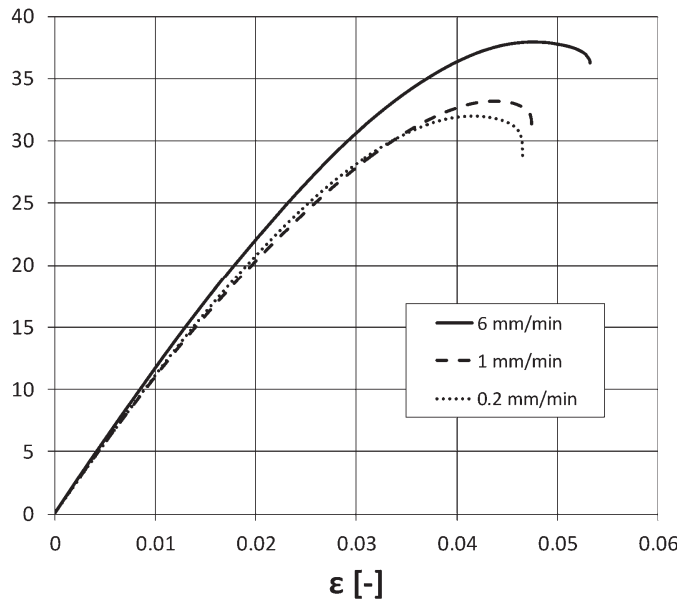

Fig. 10. Tensile stress-strain curves for different displacement curves for a) the MS-polymer Soudaseal $270 \mathrm{HS}$ and b) the epoxy Scotch Weld 9323.

For the uniaxial compression test only two different rates will be conducted, because of the reduced number of fabricated samples. The time intervals for the compression test are 2 and 10 minutes. The displacement rates corresponding to these time intervals are summarized in Table 2 for the two adhesives. Here they represent the time till $10 \mathrm{kN}$ is reached, corresponding to the load limit of the load cell.

\subsection{Results}

\subsubsection{Tensile test results}

The nominal tensile stress-strain curves are obtained by dividing the force by the initial cross section at the reduced section and the displacement by the initial testing length. Figure 10 displays the mean curves of the samples for each displacement rate for the MS-polymer Soudaseal $270 \mathrm{HS}$ and for the epoxy Scotch Weld 9323 B/A.

The main parameters with their values and standard deviations are summarized in Table 3 . The standard ETAG 002 refers to ISO 527 to obtain the Young's modulus and is calculated with Equation 1 (ETAG 002; ISO 527). 
Table 3

Main parameters and their values and the standard deviations between brackets of the tensile tests

\begin{tabular}{lcccccc}
\hline & $\begin{array}{c}\text { Load rate } \\
{[\mathrm{mm} / \mathrm{min}]}\end{array}$ & $\begin{array}{c}\varepsilon_{\text {peak }} \\
{[-]}\end{array}$ & $\begin{array}{c}\sigma_{\text {peak }} \\
{[\mathrm{MPa}]}\end{array}$ & $\begin{array}{c}\varepsilon_{\text {fail }} \\
{[-]}\end{array}$ & $\begin{array}{c}\sigma_{\max } \\
{[\mathrm{MPa}]}\end{array}$ & $\begin{array}{c}E_{t} \\
{[\mathrm{MPa}]}\end{array}$ \\
\hline Soudaseal 270 HS & 253 & $2.20(0.321)$ & $3.43(0.269)$ & $2.20(0.321)$ & $3.43(0.269)$ & 3.38 \\
& 75 & $1.59(0.458)$ & $2.89(0.439)$ & $1.59(0.458)$ & $2.89(0.439)$ & 3.30 \\
Scotch Weld 9323 B/A & 15 & $1.38(0.305)$ & $2.43(0.414)$ & $1.38(0.305)$ & $2.43(0.414)$ & 2.99 \\
& 6 & $0.049(0.0074)$ & $37.30(1.674)$ & $0.053(0.0025)$ & $36.28(1.653)$ & 1207 \\
& 1 & $0.046(0.0084)$ & $32.62(2.867)$ & $0.047(0.0076)$ & $31.33(1.406)$ & 1146 \\
& 0.2 & $0.044(0.0059)$ & $31.08(2.189)$ & $0.046(0.0083)$ & $28.80(1.768)$ & 1137 \\
\hline
\end{tabular}

With $\varepsilon_{\text {peak }}=$ peak deformation, $\sigma_{\text {peak }}=$ maximal stress, $\varepsilon_{\text {fail }}=$ deformation at failure and $\sigma_{\text {fail }}=$ stress at failure.

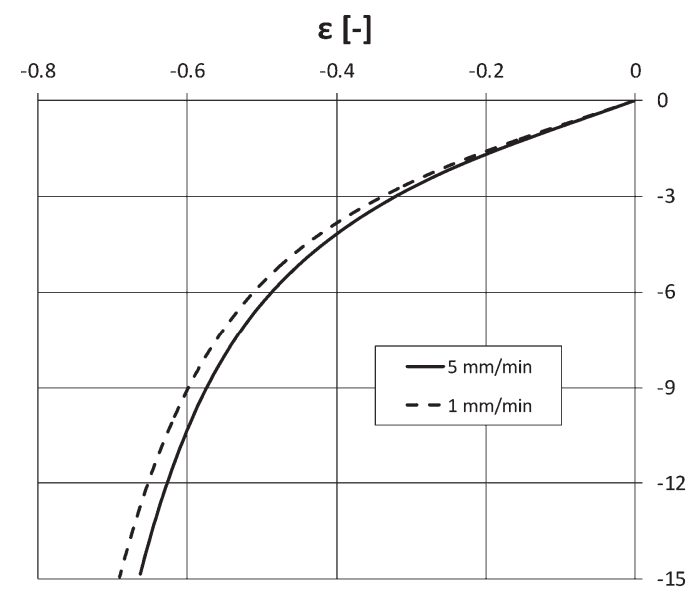

a) MS-polymer

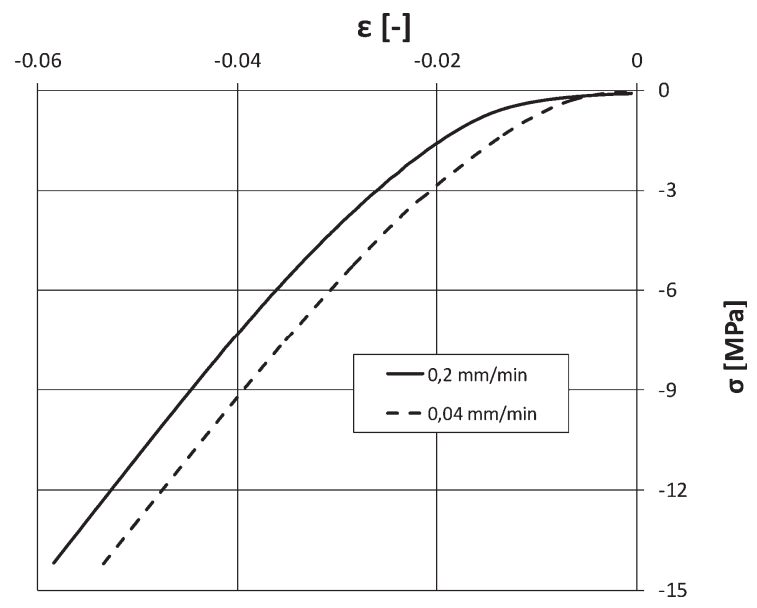

b) Epoxy

Fig. 11. Compression stress-strain curves for different displacement curves for a) the MS-polymer Soudaseal $270 \mathrm{HS}$ and b) the epoxy Scotch Weld 9323.

$$
E_{t}=\frac{\sigma_{2}-\sigma_{1}}{\varepsilon_{2}-\varepsilon_{1}}
$$

where $E_{t}=$ Young's modulus in $\mathrm{MPa}$;

$\sigma_{1}=$ the stress in MPa as measured on the deformation value of $\varepsilon_{1}=0.0005$;

$\sigma_{2}=$ the stress in MPa as measured on the deformation value of $\varepsilon_{2}=0.0025$.

For the epoxy, the Young's modulus $E_{t}$ is calculated with the proposed deformation values and for the MS-polymer with $\varepsilon_{1}=0.05$ and $\varepsilon_{2}=0.25$, due to the rapidly occurring large deformations.

\subsubsection{Compressive tests results}

The compressive stress-strain curves are obtained by dividing the force by the loaded surface and the displacement by the initial height of the samples. The mean stress-strain curves for each displacement rate are illustrated in Fig. 11 for both the MS-polymer Soudaseal 270 HS as for the 
Table 4

Main parameters and their values and the standard deviations between brackets of the compression tests

\begin{tabular}{lcccr}
\hline & $\begin{array}{c}\text { Load rate } \\
{[\mathrm{mm} / \mathrm{min}]}\end{array}$ & $\begin{array}{c}\varepsilon_{\max } \\
{[-]}\end{array}$ & $\begin{array}{c}\sigma_{\max } \\
{[\mathrm{MPa}]}\end{array}$ & $\begin{array}{c}E_{t} \\
{[\mathrm{MPa}]}\end{array}$ \\
\hline Soudaseal 270 HS & 5 & $-0.66(0.0142)$ & $-14.8(0.0751)$ & 8.42 \\
Scotch Weld 9323 B/A & 1 & $-0.69(0.00759)$ & $-14.9(0.0511)$ & 8.09 \\
& 0.2 & $-0.058(0.0026)$ & $-14.19(0.0189)$ & 15.17 \\
& 0.04 & $-0.057(0.0071)$ & $-14.35(0.336)$ & 18.81 \\
\hline
\end{tabular}

epoxy Scotch Weld 9323 B/A. The main parameters with their values and standard deviations are summarized in Table 4. The Young's modulus $E_{t}$ is calculated with Equation 1.

\subsection{Discussion of the results}

The material nonlinearity of the adhesives is clearly depicted in the graphs. Concerning the load rate dependency, for Soudaseal $270 \mathrm{HS}$ the stiffness in tension reduces by $2,4 \%$ when reducing the loading rate from 253 to $75 \mathrm{~mm} / \mathrm{min}$ and by $9,4 \%$ when reducing it from 75 to $15 \mathrm{~mm} / \mathrm{min}$. For Scotch Weld 9323 $B / A$ the stiffness is reduced by $5 \%$ and $0.8 \%$ when the displacement rate is reduced from 6 to $1 \mathrm{~mm} / \mathrm{min}$ and from 1 to $0.2 \mathrm{~mm} / \mathrm{min}$, respectively. Compared to the literature this decrease of stiffness is negligibly small (Dias et al., 2014; Lees \& Hutchinson, 1992; Yu, Crocombe \& Richardson, 2001). This is also visible on the stress-strain curves: the slopes of the curves are almost all the same (Fig. 10).

A noticeable aspect on the curves (Fig. 10) and the main parameters is that the stresses and strains at the point of failure in tension reduce remarkably as the displacement rate is reduced. Indeed, for Scotch Weld $9323 \mathrm{~B} / \mathrm{A}$ the reduction of the strains is $11,3 \%$ and $2,1 \%$ and the reduction of the stresses is $13,6 \%$ and $8,1 \%$, respectively for the displacement rate reduction from 6 to $1 \mathrm{~mm} / \mathrm{min}$ and from 1 to $0,2 \mathrm{~mm} / \mathrm{min}$. For the Soudaseal these reductions are respectively $27,7 \%$ and $13,2 \%$ for the strains and $15,7 \%$ and $15,9 \%$ for the stresses. The authors believe that this can be explained by the fact that defects have more time to grow through the specimens when the displacement rate is low.

Contrary to the expectations, when the displacement rate decreases the epoxy Scotch Weld 9323 acts stiffer in compression, whereas the MS-polymer acted more flexible. For Scotch Weld $9323 \mathrm{~B} / \mathrm{A}$ the stiffness increases by $19 \%$ with a reduction from 0.2 to $0.04 \mathrm{~mm} / \mathrm{min}$ of the displacement rate. The Young's modulus is determined at the origin of the curves, where small imperfections at the surface have a great influence on the curve, due to the very stiff behaviour. Because of that problem, the stiffness of Scotch Weld $9323 \mathrm{~B} / \mathrm{A}$ in compression is determined by means of Equation 1, using $\varepsilon_{1}=0.03$ and $\varepsilon_{2}=0.04$. The Young's modulus for a displacement rate of $0.2 \mathrm{~mm} / \mathrm{min}$ is $322.8 \mathrm{MPa}$ and for a displacement rate of $0.04 \mathrm{~mm} / \mathrm{min}$ it is $345.1 \mathrm{MPa}$, a difference of $6.4 \%$. This is also visible on the stress-strain curves: the slopes of the curves are almost identical (see Fig. 11b). Due to its softer behaviour, the stress-strain curve of the MS-polymer is less sensitive to small imperfections at the surface. Therefore the difference in stiffness in compression can be calculated using Equation 1, with standard values of $\varepsilon_{1}$ and $\varepsilon_{2}$. The stiffness decreases by $3.9 \%$ when the displacement rate is reduced from 5 to $1 \mathrm{~mm} / \mathrm{min}$ (see Fig. 11a).

As expected, the difference between the stiffness of the two selected adhesives is significant. It is almost a factor of 400 . This difference was also observed at failure, the more flexible MS-polymer 
failed at large strains while the epoxy failed at low strains. However the epoxy failed at a ten times higher force than the MS-polymer.

\section{Parametric study on the effects of mechanical and geometrical parameters}

\subsection{Method}

In this section, the effects of geometrical and mechanical parameters are studied with nonlinear FEA, modelling a point-fixing under tensile load. The adhesive of point-fixing under tensile load are subjected to high confined stress state due to large diameter-thickness ratio. To separately investigate the nonlinearity due to confinement effect from the material nonlinearity, in this section the adhesive material is assumed to be linear elastic. A parametric analysis is performed to investigate the effects of four key parameters: Young's modulus $E$, Poisson's ratio $v$, connector diameters $D$ and adhesive thickness $t$. For each numerical analysis of the parametric study one parameter value is changing while the other parameters are kept at a reference value. The obtained results are then postprocessed to study the effects related to each parameter. In particular, joint stiffness and adhesive stress distributions under tensile force are investigated. To do so, two groups of curves are derived, namely: load versus relative displacement and adhesive stress versus normalized distance. Maximum principal stress, Von Mises stress and stress triaxiality are computed. To quantify the stress peaks and the nonlinear stress distribution, two stress factors are here defined by Equation 2, $\alpha_{\sigma, \max }$ and $\alpha_{\sigma, m i s}$, as ratio between the actual nonlinear stress values and the nominal uniform stress, usually called engineering stress. Therefore, these coefficients describe the deviation of the nonlinear stress distribution from the uniform nominal one due to nonlinearity.

$$
\alpha_{\sigma, \max }=\frac{\sigma_{\max }}{\sigma_{\text {nom }}} ; \alpha_{\sigma, \text { mis }}=\frac{\sigma_{\text {mis }}}{\sigma_{\text {nom }}} ; \eta=-\frac{p}{\sigma_{\text {mis }}} ;
$$

With:

$$
\sigma_{\text {nom }}=\frac{F}{A} ; p=-\frac{\operatorname{trace}(\sigma)}{3} ; \sigma_{m i s}=\sqrt{\frac{3}{2} \sigma^{\prime}: \sigma^{\prime}} ;
$$

where in the previous expressions $\sigma_{\text {nom }}$ is the nominal stress (force divided by adhesive surface area), $\sigma_{\max }$ and $\sigma_{\text {mis }}$ are respectively the maximum principal stress and the Von Mises stress, $\eta$ is the stress triaxiality, $p$ is the hydrostatic pressure, $\sigma$ is the stress tensor and $\sigma^{\prime}$ is the deviatoric part of the stress tensor.

\subsection{Numerical model}

The adhesive connection is numerically analysed by a three-dimensional model realised by means of the finite element software ABAQUS (SIMULIA, 2011). The geometry consists of a circular metal connector (stainless steel AISI 316L) adhesively bonded/connected to a rectangular glass plate ( $300 \mathrm{~mm} \times 150 \mathrm{~mm} \times 19 \mathrm{~mm}$ ) (see Fig. 12). The presence of the threaded hole in the metal connector is taken into account in the model.

Only half geometry of the connection is implemented due to the symmetry along the $x$-axis (see Fig. 13a). Half geometry is used rather then quarter since the same model is used also in further 


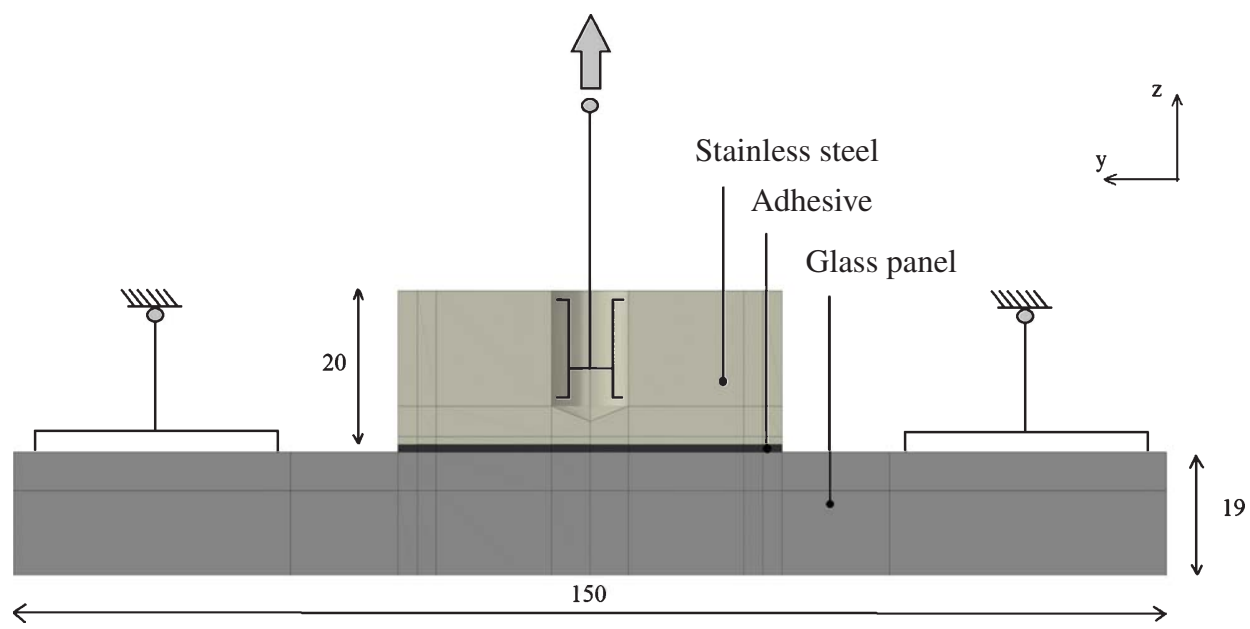

Fig. 12. Scheme of numerical model: multiple-point-constrains, displacement constrains and load application.

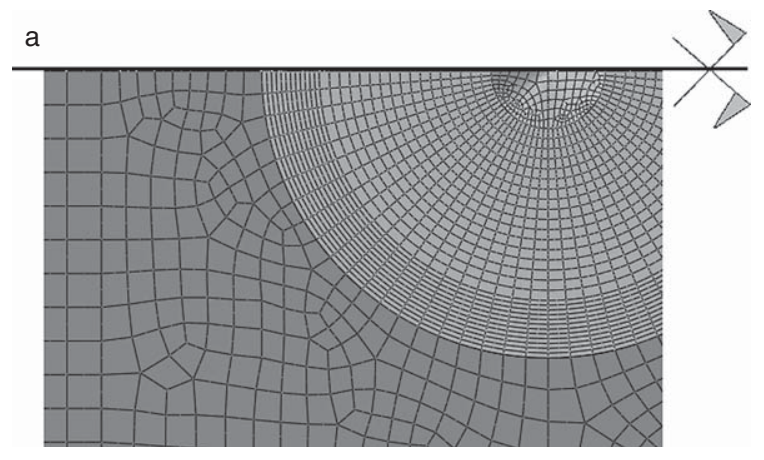

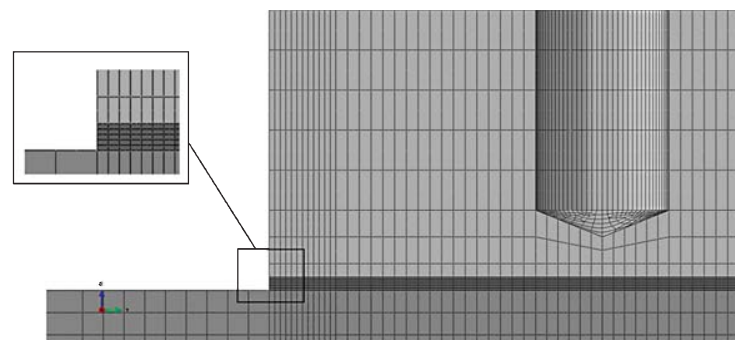

Fig. 13. a) Mesh pattern of the numerical model. b) Zoom of the mesh refinement at the adhesive level.

analysis with shear load (not here presented). The load is applied to the metal connector by means of multiple-points-constraints between the bolt surface and a reference point of load introduction. The vertical displacements of the glass plate are constrained at the left and right side of the glass (see Fig. 12).

Three-dimensional solid finite elements are used to mesh the model geometry. In particular, 20-nodes quadratic brick elements with reduced integration were used to perform the nonlinear numerical analysis (C3D20R, see Fig. 14). The mesh was refined at the adhesive level to increase the accuracy of the stress field computation. For the same reason, an additional mesh refinement is also introduced at the edge of the adhesive, where the stress peaks are expected to occur (Fig. 13b). Static step-by-step numerical analyses are performed by means of the implicit ABAQUS solver. Finite deformation theory is used in each step of the calculations.

To perform the parametric study, an algorithm has been developed, which makes use of automatic scripts written in Python language. Given as input a set of parameter values, the algorithm automatically performs the creation of the model, equation solution, extraction of data from the results' database and post-processing of data in final parametric curves. 

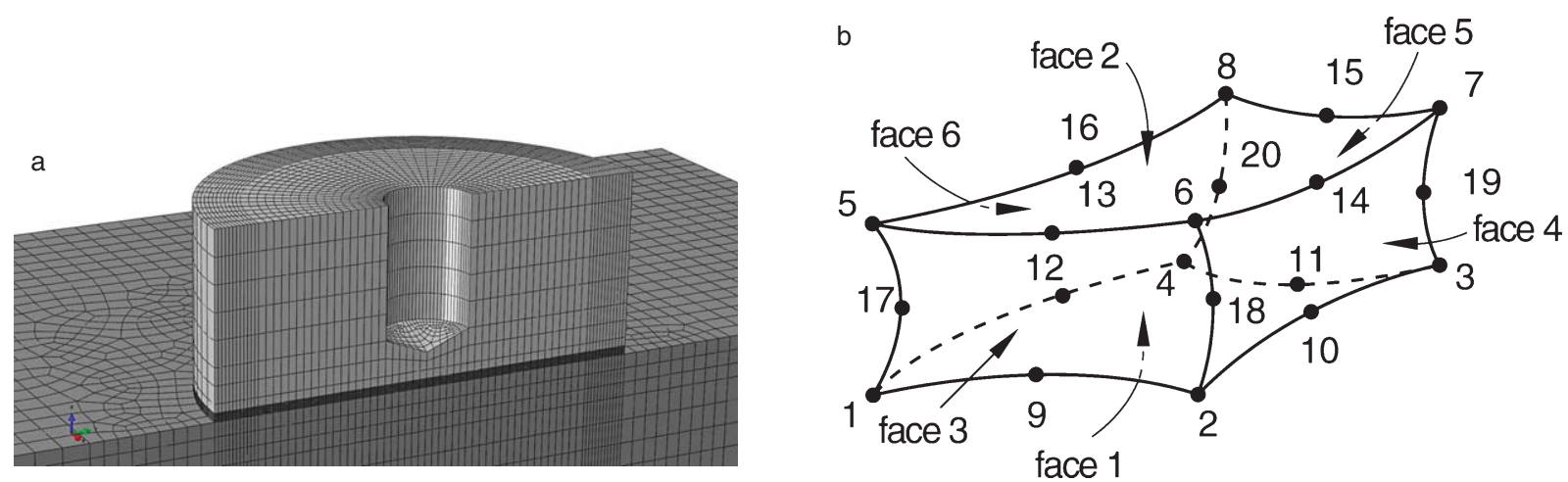

Fig. 14. a) 3D view of the numerical model. b) Quadratic 20-node element (SIMULIA, 2011).

Table 5

Parametric analysis: set of parameters' value (reference values in bold-italic based on SG and TSSA at $23^{\circ} \mathrm{C}$ )

\begin{tabular}{lll}
\hline Parameter & Symbol [unit] & Values \\
\hline Young's modulus & $E[M P a]$ & $5,10,20,60,125,200$ \\
Poisson's ratio & $v[-]$ & $\mathbf{0 . 4 5 0 , 0 . 4 7 0 , 0 . 4 8 0 , 0 . 4 9 0 , 0 . 4 9 4 , 0 . 4 9 8}{ }^{1)}$ \\
Diameter & $D[\mathrm{~mm}]$ & $\mathbf{3 5}, \mathbf{4 0 , 4 5 , 5 0 , 5 5 , 6 0}$ \\
Thickness & $\mathrm{t}[\mathrm{mm}]$ & $\mathbf{0 . 5}, \mathbf{0 . 8}, \mathbf{1}, \mathbf{2}, 2.5,3$ \\
\hline
\end{tabular}

1)(Bennison \& Davies, 2008; Callewaert, 2011).

The results of a mesh and element study state that quadratic elements should be preferred to linear ones for convergence purpose. Furthermore, regarding the stress distribution in the adhesive, it resulted that at least 5 elements through thickness should be used to model the adhesive thickness with sufficient accuracy.

\subsection{Results of the parametric study}

The effects of several parameters on the adhesive point connection behaviour are studied by parametric analysis. The effect of Young's modulus $E$, Poisson's ratio $v$, diameter of the metal connectors $D$ and adhesive's thickness $t$ are here presented for tensile load condition. All the investigated values are collected in Table 5. The reference values are indicated in bold. As described above, the results are presented by load-displacement curves and normalized stress distribution versus normalized distance. Stresses are extracted in the middle of the adhesive layer, i.e. cutting the adhesive at half thickness. It should be mentioned that usually after the curing process the actual adhesive thickness might be different than the initial one. Only the current thickness values have to be considered for the stress calculation. Therefore, in the following paragraphs, with 'thickness' is meant the actual measured thickness value of the adhesive after the curing process.

The first parametric analysis showed a large sensitivity of the results to the adhesive's Young's modulus $E$, both in terms of stiffness and stress distribution (see Figs. 15 and 16). Because of that, two groups of parametric analyses were then performed: one for a lower value of $E$ (indicated as 'soft adhesive', $E=5 \mathrm{MPa}$ ) and one for a higher value of $E$ (indicated as 'stiff adhesive', $E=200 \mathrm{MPa}$ ). 

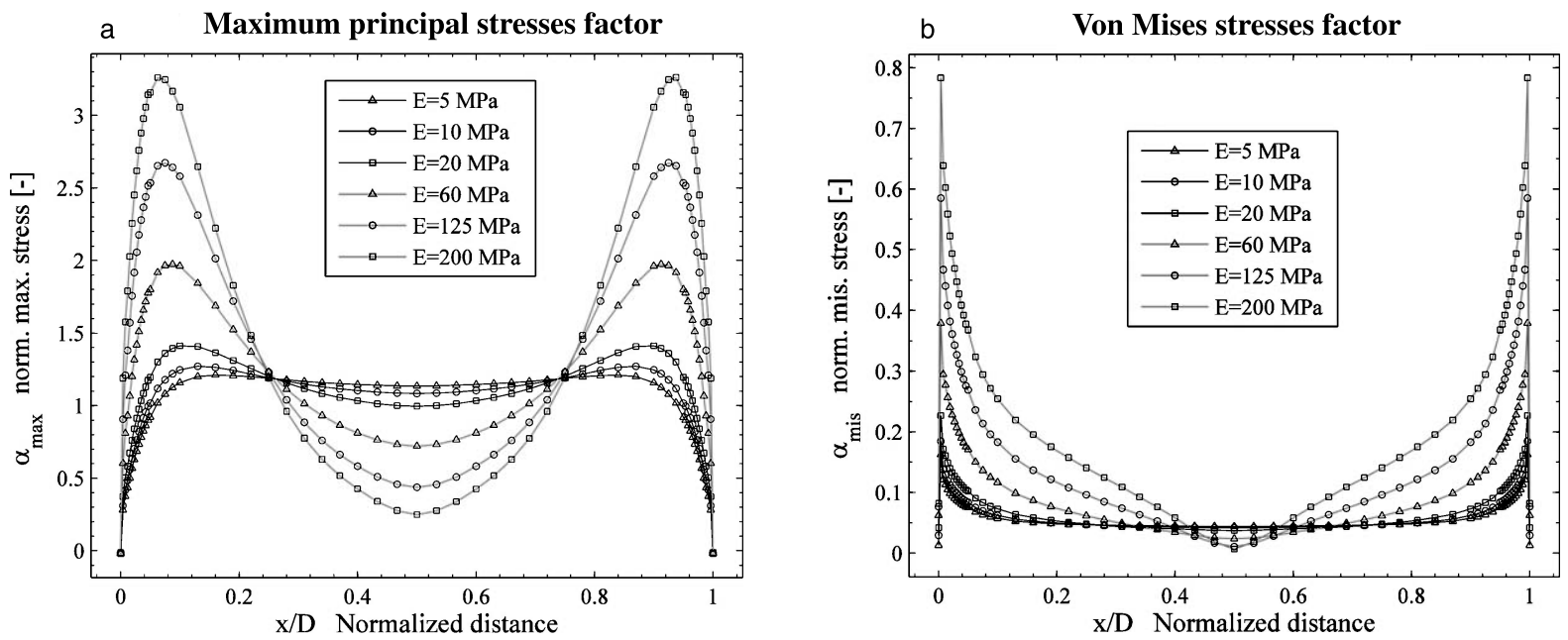

Fig. 15. Stress distribution in the adhesive for different values of Young's modulus of the adhesive material: maximum principal stresses (a) and Von Mises stresses (b).
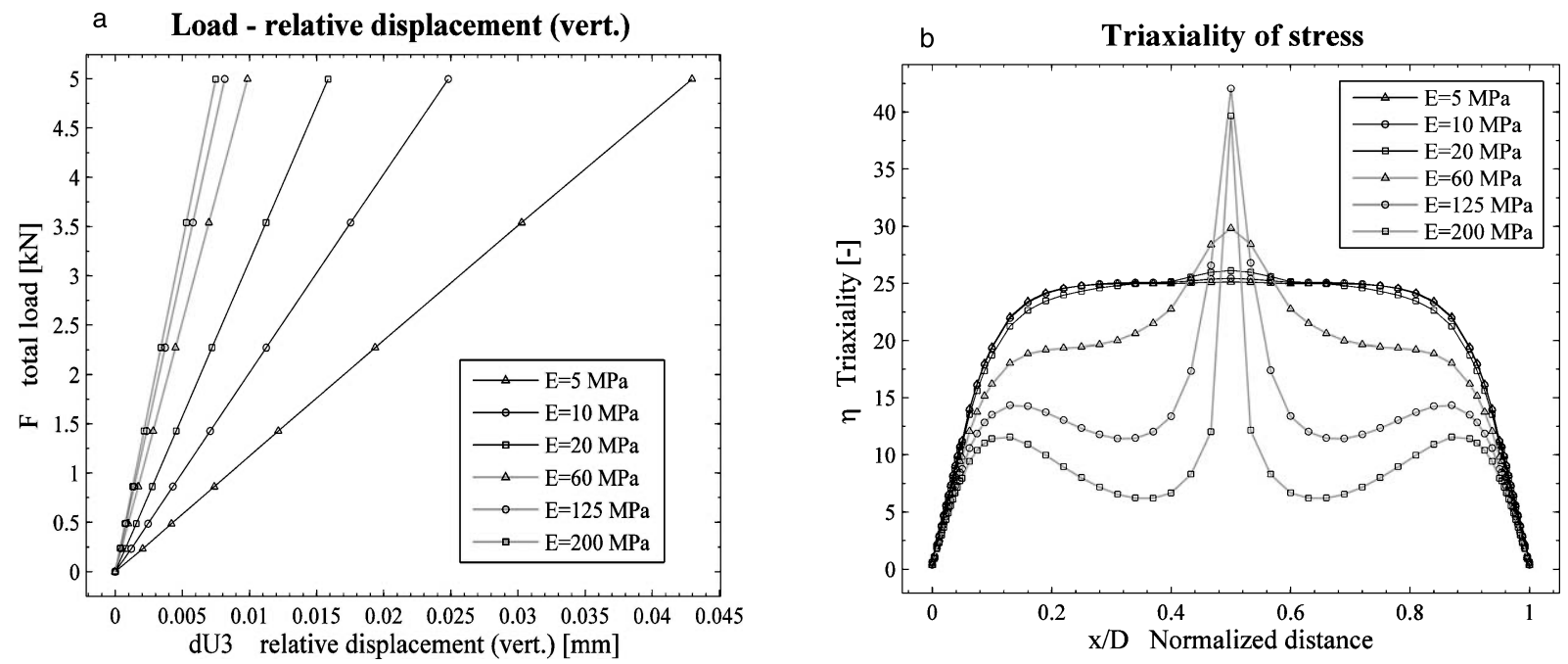

Fig. 16. Load-displacement curve (a) and stress triaxiality distribution (b) for different values of Young's modulus of the adhesive material.

\subsubsection{Young's modulus}

Figures 15 and 16 depict the effect of the Young's modulus $E$ of the adhesive material. The investigated values are $5 \mathrm{MPa}, 10 \mathrm{MPa}, 20 \mathrm{MPa}, 60 \mathrm{MPa}, 125 \mathrm{MPa}$ and $200 \mathrm{MPa}$. These range of values are defined according to the stiffness of the adhesive material investigated at EPFL, i.e. SG, SentryGlas, and TSSA, Transparent Structural Silicone Adhesive. Values are taken from (Bennison \& Davies, 2008; Callewaert, 2012; Sitte et al., 2011). 

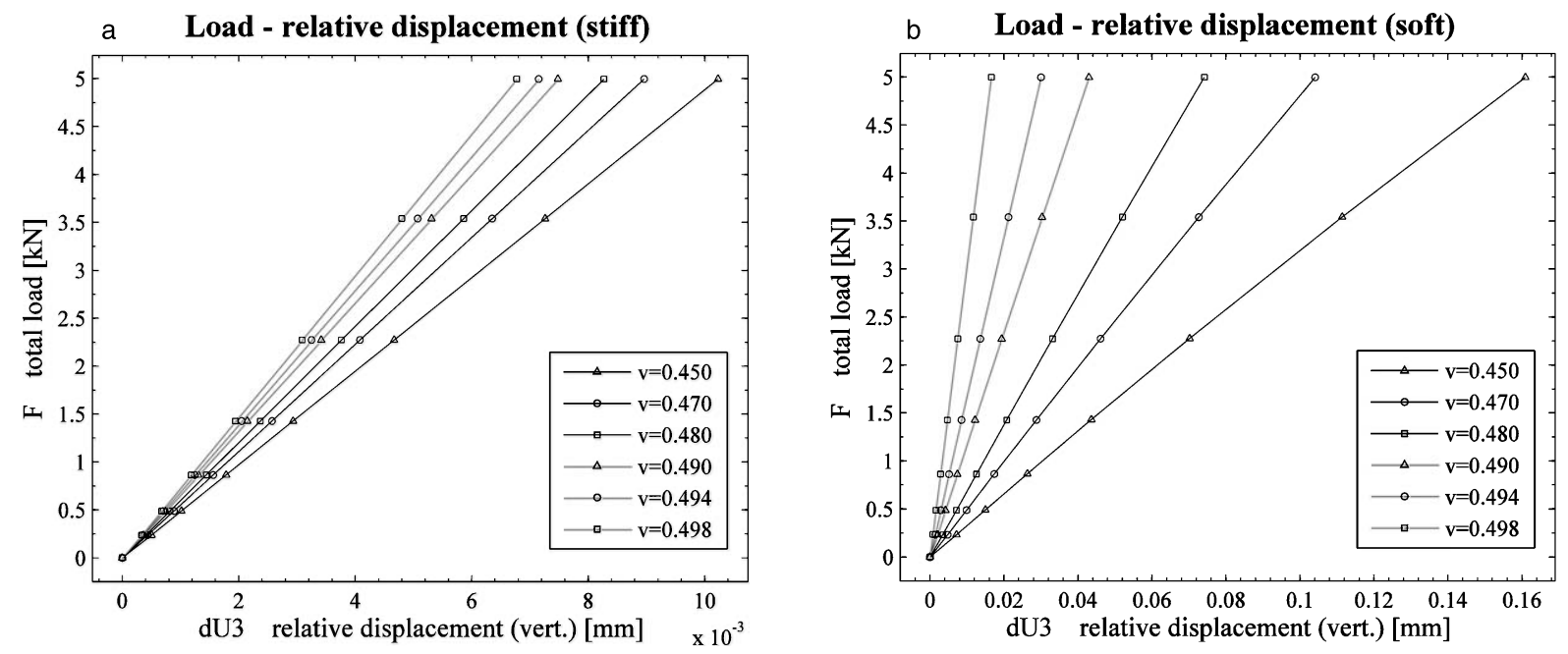

Fig. 17. Load versus relative displacement for different values of Poisson's ratio.
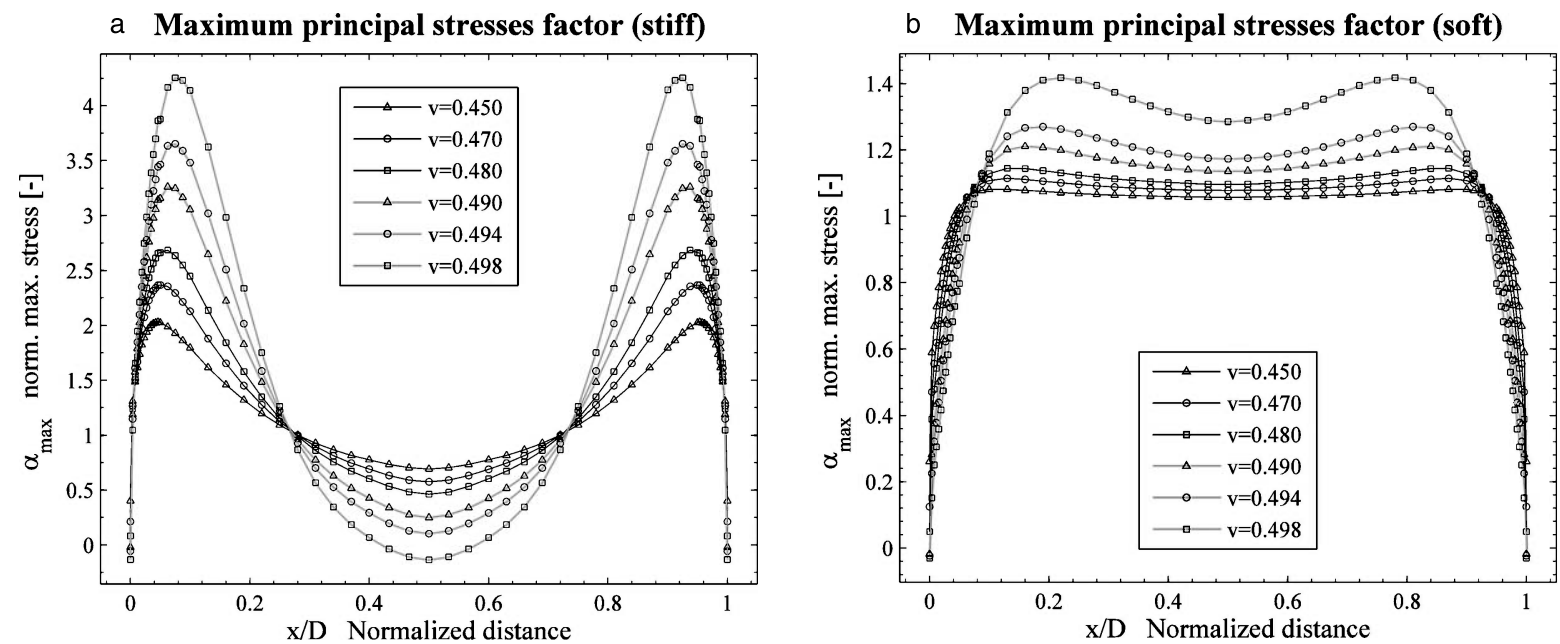

Fig. 18. Maximum principal stress distribution in the adhesive for different values of Poisson's ratio.

\subsubsection{Poisson's ratio}

Figures 17-19 depict the effect of the Poisson's ratio $v$ of the adhesive material. The investigated values are 0.450, 0.470, 0.480, 0.490, 0.494 and 0.498, from Bennison et al. (2008), Callewaert (2012) and Sitte et al. (2011) for SG and TSSA.

\subsubsection{Diameter}

Figures 20-22 depict the effect of the metal connectors' diameter $D$. The investigated values are $35 \mathrm{~mm}, 40 \mathrm{~mm}, 45 \mathrm{~mm}, 50 \mathrm{~mm}, 55 \mathrm{~mm}$ and $60 \mathrm{~mm}$. These values correspond to typical dimensions of bolted point-fixings commonly used in glass structures and facades. 

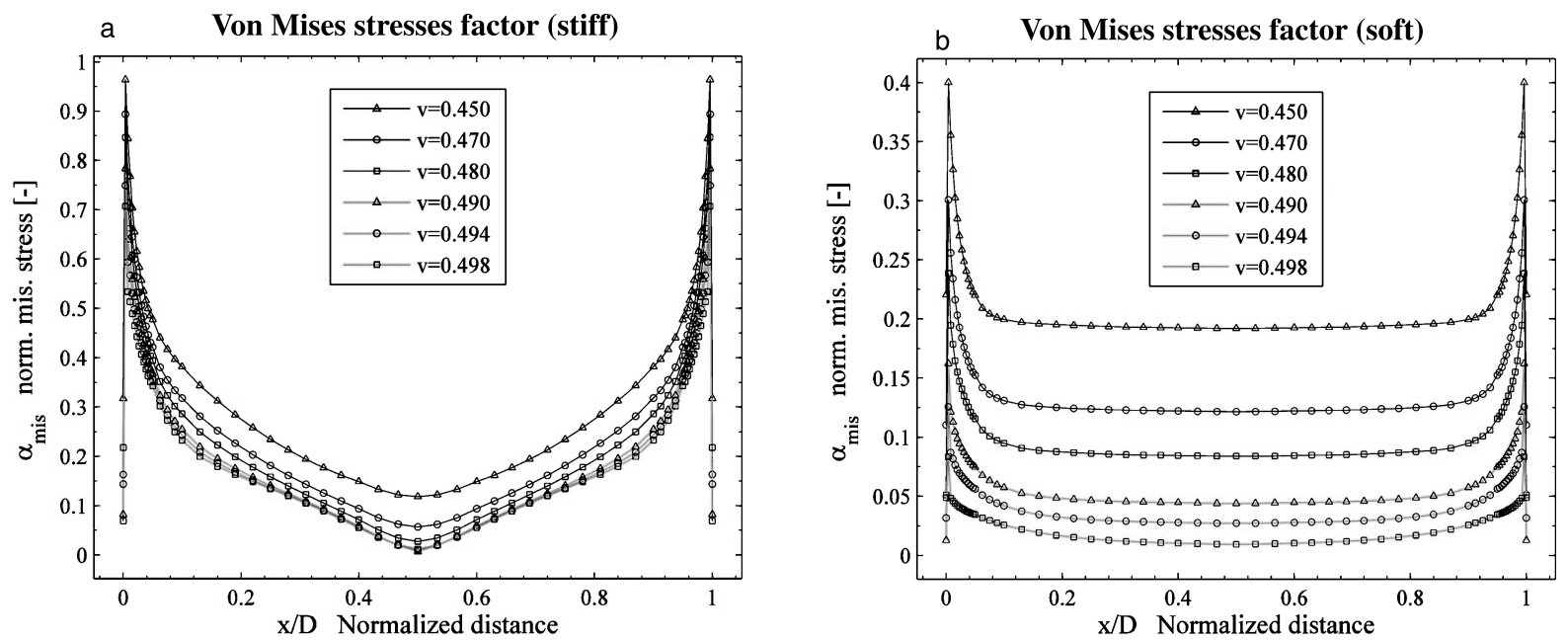

Fig. 19. Von Mises stress distribution in the adhesive for different values of Poisson's ratio.
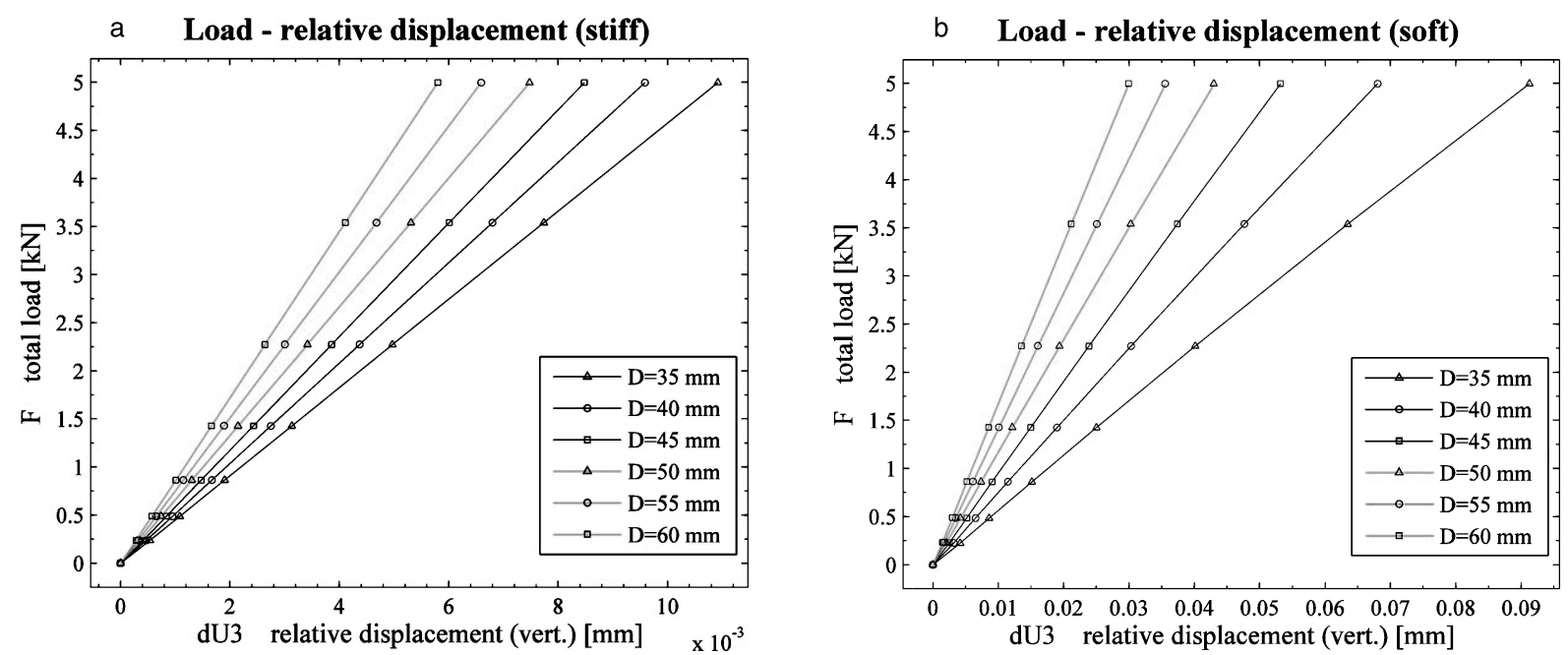

Fig. 20. Load versus relative displacement for different values of diameter.

\subsubsection{Thickness}

Figures 23-25 depict the effect of the adhesive thickness $t$. The investigated values are $0.5 \mathrm{~mm}$, $0.8 \mathrm{~mm}, 1.0 \mathrm{~mm}, 2.0 \mathrm{~mm}, 2.5 \mathrm{~mm}$ and $3.0 \mathrm{~mm}$. These values correspond to a typical range of thickness used in adhesive connections for glass structures.

\subsection{Discussion of the results}

The collected numerical results demonstrate that large nonlinearity characterizes the behaviour of adhesive point-fixings, even in case of simple load conditions. Both the stress factors (here defined as ratio between stress peaks and nominal stress) and the global stiffness of the connections result to be strongly dependent on the mechanical and geometrical parameters here investigated. This indicates 
a Maximum principal stresses factor (stiff)

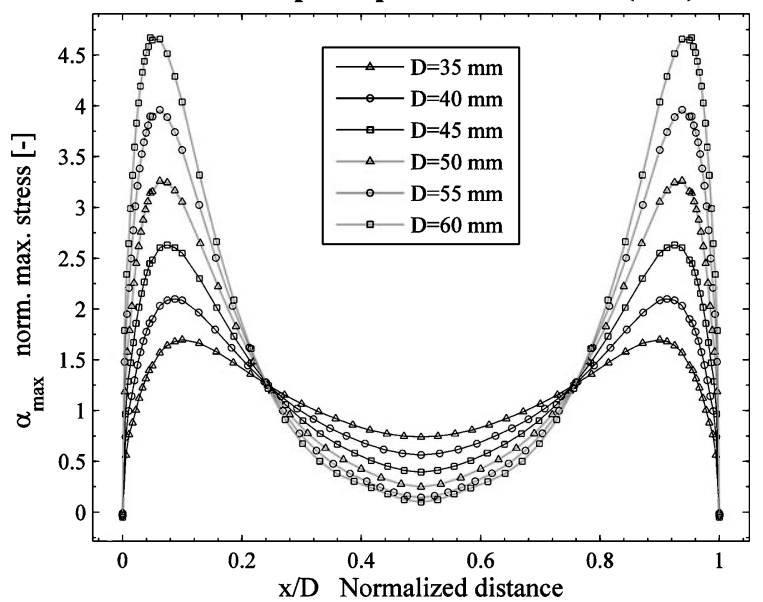

b Maximum principal stresses factor (soft)

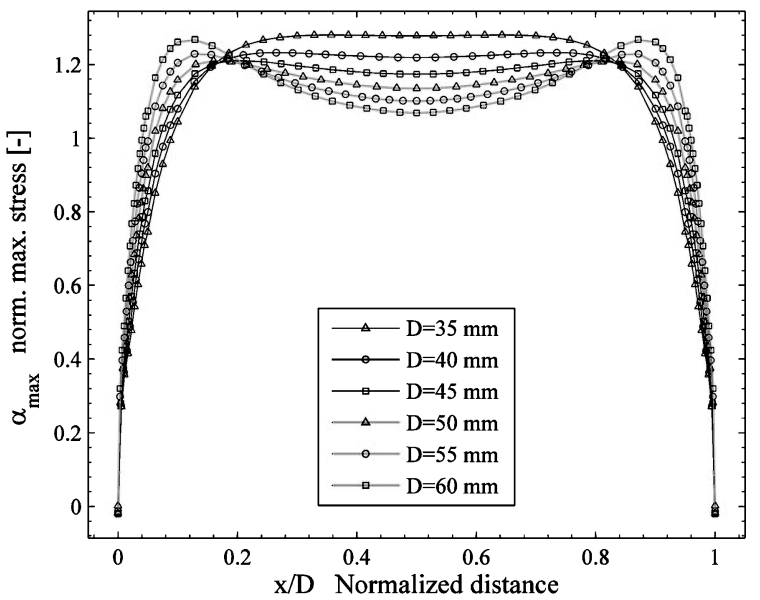

Fig. 21. Maximum principal stress distribution in the adhesive for different values of diameter.
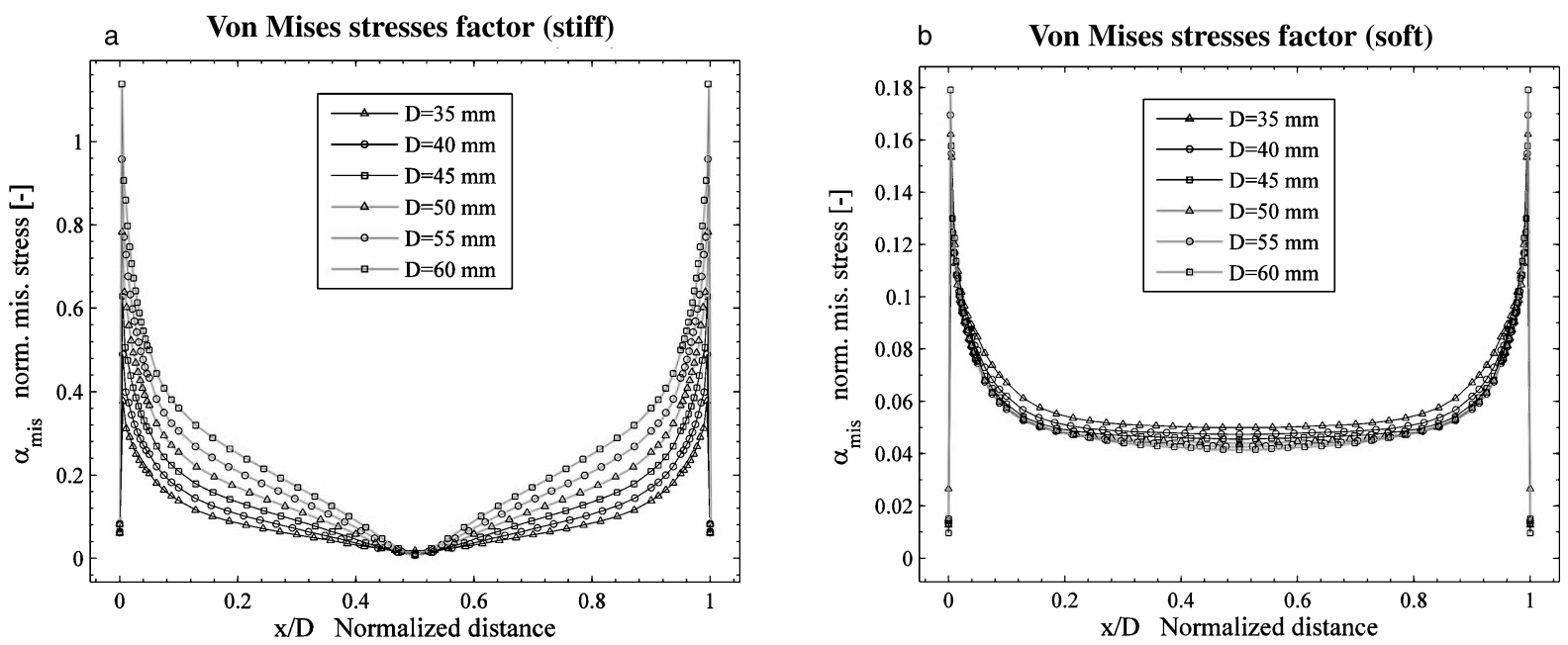

Fig. 22. Von Mises stress distribution in the adhesive for different values of diameter.

that experimental tests carried out to determine the maximum failure stress of the adhesive should always be performed together with an accurate calculation of the actual stress peak occurring in the connection during the test.

Figures 16, 17, 20, and 23 show that the connection's stiffness is a function of both the Poisson's ratio and joint geometry. This is because, once subjected to longitudinal elongation $\varepsilon_{z z}$, the adhesive material tends to exhibit transversal deformation $\varepsilon_{y y}$ due to the Poisson effect (see Equation 4 and Fig. 26a). However, the boundary conditions of adhesive joints constrain this transversal contraction resulting in transversal deviatoric stresses, conversely to what occurs during uniaxial tensile tests on bulk material where the transversal deformations are totally free to occur (Fig. 26b). These deviatoric shear stresses are higher close to the edge of the adhesive (see Fig. 15b). 

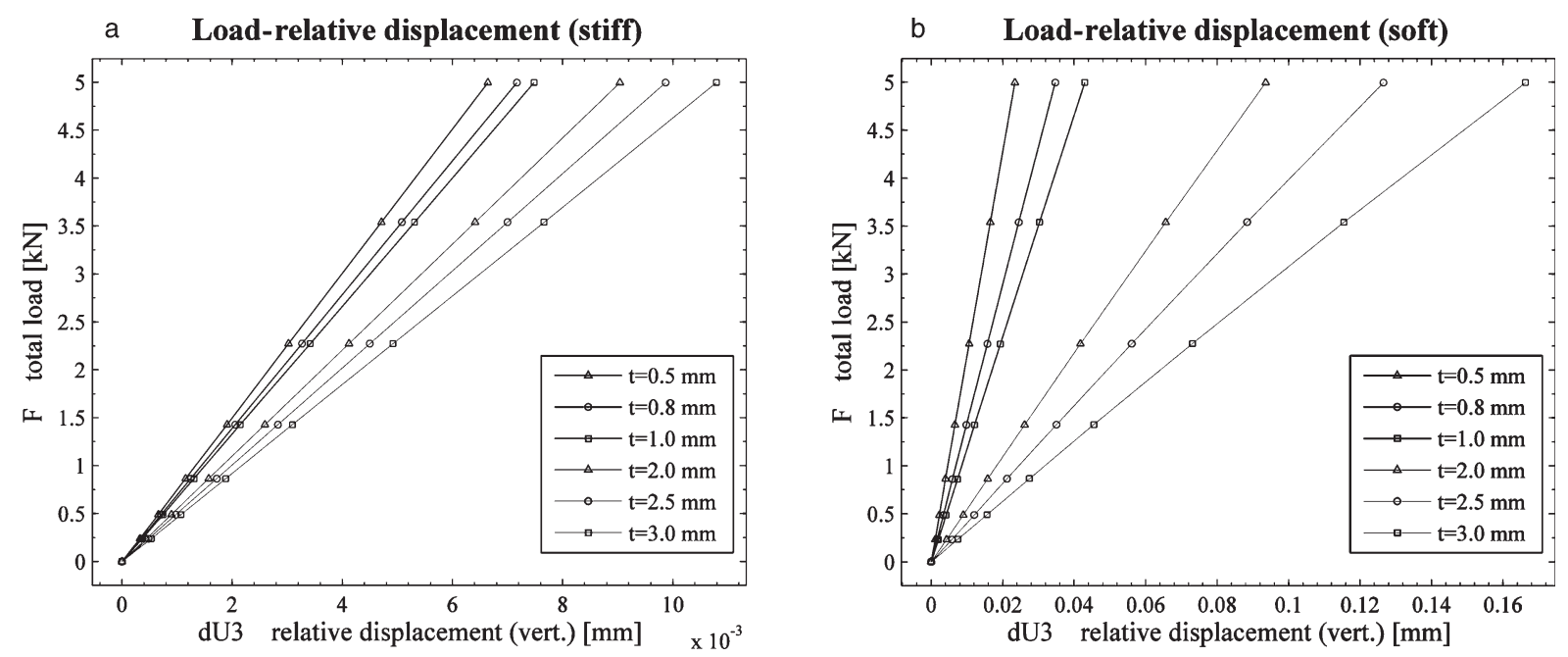

Fig. 23. Load versus relative displacement for different values of thickness.

a Maximum principal stresses factor (stiff)

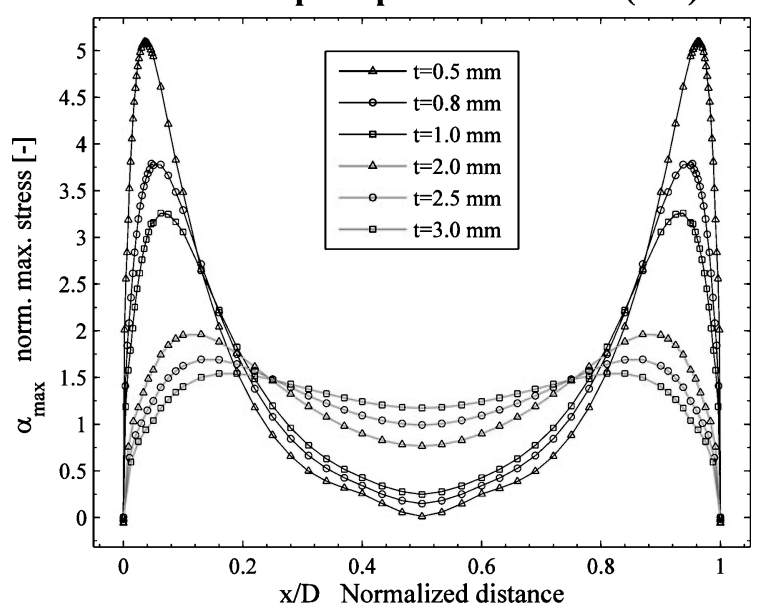

b Maximum principal stresses factor (soft)

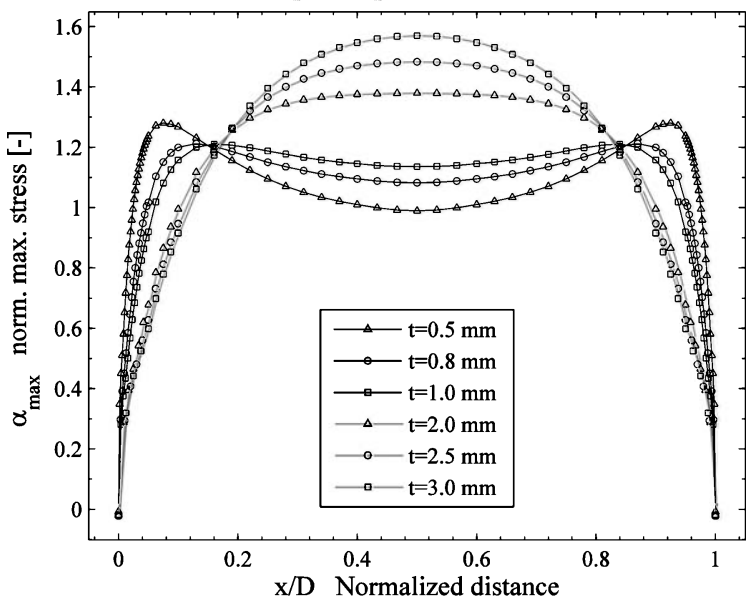

Fig. 24. Maximum principal stress distribution in the adhesive for different values of thickness.

$$
\varepsilon_{y y}=-v \cdot \varepsilon_{z z}
$$

It is also observed that this constraining effect, which is the cause of the nonlinearity of the stress distributions in the adhesive (see Figs. 16 and 19), increases with higher values of diameter and lower values of thickness. This phenomenon can also be observed in Figs. 17, 20, and 23, since the joint stiffness increases with higher value of the Poisson's ratio, larger value of diameter and lower value of adhesive thickness.

Furthermore, the numerical results demonstrate that the variation of both mechanical and geometrical parameters induces large variation of maximum values of the stress peak. This occurs for both the maximum principal stress (Figs. 21 and 24) and the Von Mises stress (Figs. 22 and 25). Higher 

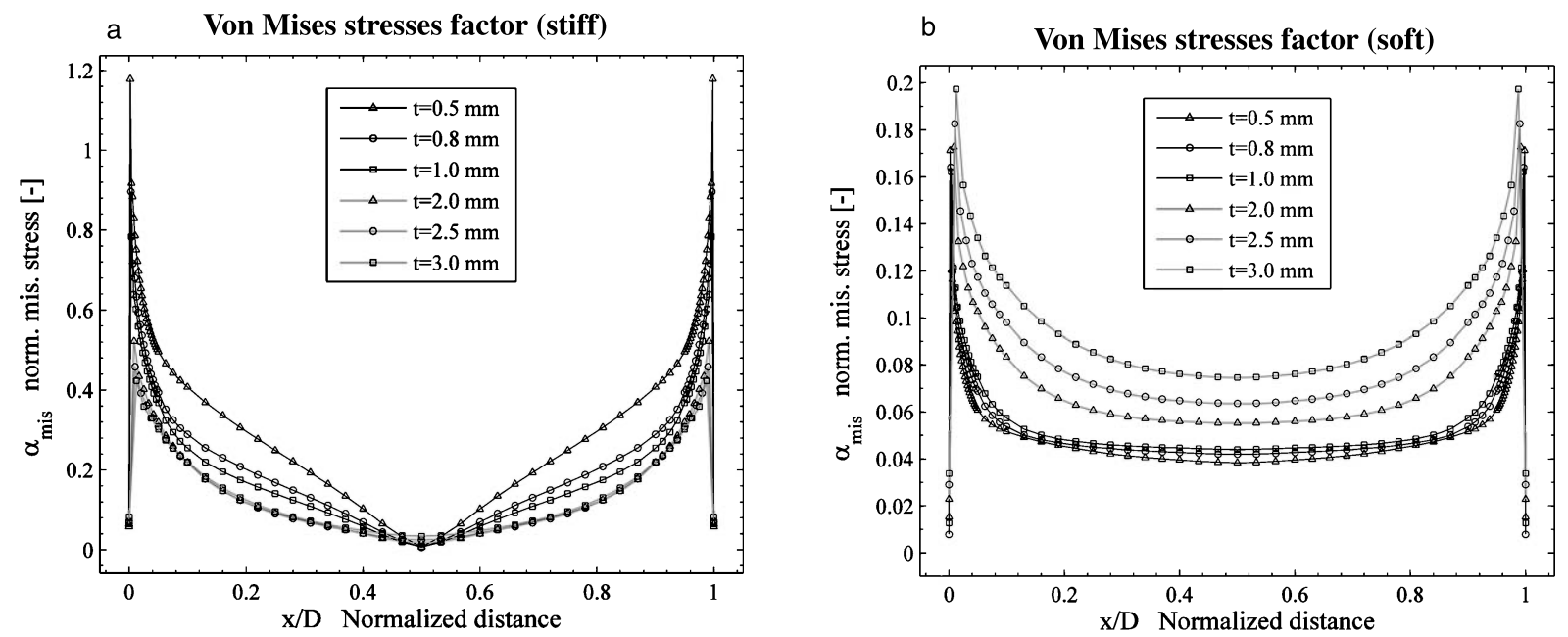

Fig. 25. Von Mises stress distribution in the adhesive for different values of thickness.

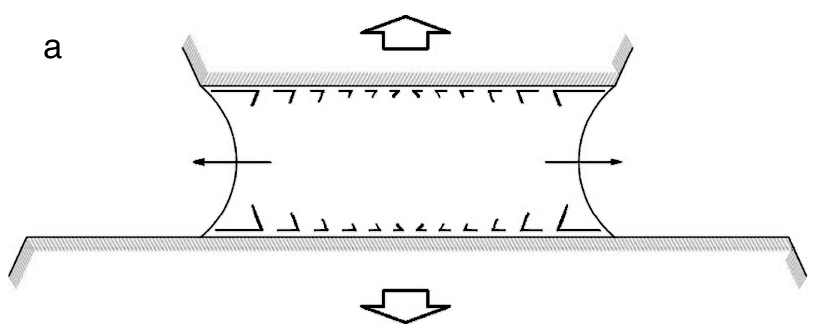

b

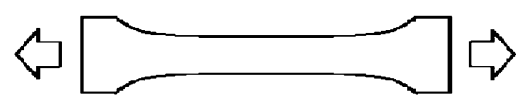

Fig. 26. a) Transversal stresses in the adhesive connections due to the Poisson's effect. b) Scheme of uniaxial tensile test on bulk adhesive material: free transversal deformation.

stress peaks are observed in the case of stiff adhesive rather than soft adhesive (see for example Fig. 24). In addition, the location of this value is also dependent on diameter and thickness values (see Figs. 21 and 24). Finally, remarkable differences in the stress triaxiality distribution were also observed between soft and stiff connection (see Fig. 16a).

More details on the effect of each parameter are listed below. In particular, the global stiffness of the connection:

- Increases with the Young's modulus (see Fig. 16a), because the bulk adhesive material is stiffer;

- Increases with the diameter (see Fig. 20), because when the diameter is larger the adhesive is more constrained against transversal contraction;

- Decreases with the adhesive thickness (see Fig. 23), because larger thickness reduce the constrain effect;

- Increases with the Poisson's ratio (see Fig. 17), because with larger values of Poisson's ratio the material tends to be incompressible, i.e. stiffer to volume changes.

While the peak of maximum principal stress:

- Increases with Young's modulus (see Fig. 15), because the bulk adhesive material gets stiffer and the effect of transversal constrain is enlarged; 
- Increases with higher Poisson's ratio (see Figs. 18 and 19), because the material tends to be incompressible and therefore more rigid against volume changes which leads to a higher stress peak;

- Changes in general with diameter and thickness, with much larger variation in case of stiff adhesives than in case of soft adhesives (see difference between Fig. 21a and 21b).

- Increases with higher $D / t$ ratio, in case of stiff adhesives (see Figs. 21 and 24), because at large diameter-thickness ratios, the adhesive is more constrained against transversal contraction.

From Figs. 20 and 23 it can then be derived that the stiff adhesive exhibits extremely small deformation during the tests, i.e. in the range of $10^{-3}$ and $10^{-2} \mathrm{~mm}$. It is therefore recommended to include the glass deformability in the numerical simulations of this type of joints. This is because the hypothesis of rigid substrate, which is often adopted in literature for adhesive joints, may not be satisfied and thus it may lead to different stress distribution. In that regard, if one considers to apply the $5 \mathrm{kN}$ load (as it is in Fig. 20a) to the glass panel only, and conservatively consider the glass as a beam fully constrained at the supports, the displacement can be estimated by $\mathrm{P} \cdot \mathrm{L}^{3} /(\mathrm{k} \cdot \mathrm{E} \cdot \mathrm{J})$, where $\mathrm{P}$ is the load, $\mathrm{L}$ is the span, $E$ is the glass Young's modulus, $J$ is the glass moment of inertia and $k$ is equal to 192 for concentrated load and to 384 for distributed load. This leads to displacements between $4 \cdot 10^{-3} \mathrm{~mm}$ and $2 \cdot 10^{-3} \mathrm{~mm}$, which is comparable to the deformation exhibited by stiff adhesive material (see for example Fig. 20a).

Furthermore, it is also observed that, for soft adhesive, an optimum value of diameter/thickness ratio is approximately around $45[\mathrm{~mm} / \mathrm{mm}$ ] (see Fig. $21 \mathrm{~b}$ ), when the other parameters are equal to the reference one.

Further works will focus on obtaining a semi-empirical analytical expression able to provide the value of the stress factor for certain adhesive and connection geometry. This will permit to evaluate the stress factor value, providing the connection dimension, adhesive thickness, Young's modulus and Poisson's ratio. This way the maximum load of the connection can be analytically calculated, given the maximum adhesive stress obtained from tests. Alternatively, given the applied load, the stress peak in the adhesive can be analytically calculated.

\section{Conclusions}

Firstly, the material tests here presented confirm that the adhesives behave nonlinearly under large deformations. The stiffness of the two selected adhesive does not depend on the displacement rate for the three tested displacement rates. It is also observed that stress and strain at failure in tension reduce as the displacement rate is reduced. In selecting a suitable adhesive for adhesive point-fixings several aspects should be considered together. Flexible adhesives as MS-polymers and silicones will fail at large strains, which benefits to compensate differential thermal expansions. In contrast, stiffer epoxies and acrylates will fail at lower strains but have a higher failure load, which results in smaller and more visually appealing diameters.

Secondly, the parametric analysis here presented demonstrates that adhesive connections exhibit a quite complex behaviour with large nonlinearity that cannot be neglected. The stress distribution within the adhesive deviates from the uniform nominal stresses, even in case of simple load condition. The actual maximum stress peak results to be in general higher than the nominal one. In some cases the stress peak is more than 4 times higher than the nominal one. The joint stiffness is not only depending on the Young's modulus but also on the Poisson's ratio and diameter-thickness ratio. 
This is due to the high confinement state of the thin adhesive layer. The response of the connections appears to be dependent on both mechanical and geometrical parameters. These parameters have significant effects on both the stress distribution and the global stiffness of the joint. Stiff adhesives yield larger stress peaks than soft adhesives. Stiff adhesives are also more sensitive to parameter variation than soft adhesives.

In conclusion, this work showed that large nonlinearity is involved when adhesive point-fixings are used. This means that (i) the nonlinear stress strain curve must be obtained for each adhesive for implementation in numerical modelling and (ii) accurate numerical simulation should be performed to calculate the stress peak occurring in the adhesive.

\section{Acknowledgments}

The authors would like to thank the Flemish government agency for Innovation by Science and Technology (Grant N ${ }^{\circ} 121043$ ) and the Swiss National Science Foundation (Grants 200021_134507 and 200020_150152) for funding the present research. In addition, The COST Action TU0905 "Structural Glass - Novel Design Methods and Next Generation Products" is also acknowledged for facilitating and providing a useful research network for this study. The ArcelorMittal Chair of Steel and Façade Engineering at the University of Luxembourg is gratefully acknowledged for the use of equipment to fabricate the adhesive bulk specimens. The Materials Science and Engineering department of Ghent University is acknowledged for the use of the testing equipment. Also Soudal (BE) is gratefully acknowledged for providing the MS-polymer adhesive Soudaseal 270 HS.

\section{References}

Belis, J., Callewaert, D., \& Van Hulle, A. (2011a). Bouwen met glas en adhesieven - Praktische gids voor ontwerper en uitvoerder (in Dutch), Ghent University, Ghent, Belgium.

Belis, J., Van Hulle, A., Out, B., Bos, F., Callewaert, D., \& Poulis, H. (2011b). Broad screening of adhesives for glass-metal bonds. In 12th International Conference on Architectural and Automotive Glass (Glass Performance Days 2011) (pp. 286-289). Glass Performance Days.

Bennison, S. J., Qin, M. H., \& Davies, P. S. (2008). High-performance laminated glass for structurally efficient glazing, Innovative light-weight structures and sustainable façades, 1-12.

Beyer, J. (2007). Ein Beitrag zum Bemessungskonzept für punktgestützte Glastafeln (Doctoral dissertation). Technischen Universität Darmstadt, Germany.

Callewaert, D. (2012). Stiffness of glass/ionomer laminates in structural application. (Doctoral dissertation). Ghent University, Belgium.

Dias, V., Hechler, O., \& Odenbreit, C. (2012). Determination of Adhesives Properties for Non-linear Numerical Simulations of Structural Steel-Glass Connections. Proceedings of Challenging Glass, 3, 195-207.

Dias, V., Odenbreit, C., Hechler, O., Scholzen, F., \& Ben Zineb, T. (2014). Development of material law for silicone to simulate structural adhesive connections. Engineered Transparency Handbook, 323-333.

Dispersyn, J., Van der Biest, T., \& Belis, J. (2014). Experimental research on the failure of adhesive point-fixings between annealed and metal under uniaxial load. Proceedings of Challenging Glass, 4 \& COST TU0905 Final Conference, 339-346.

EN ISO 572-2: Determination of Tensile Properties of Plastics. CEN, 1996.

ETAG 002 Guideline for European Technical Approval for Structural Sealant Glazing Kits (SSGK), European Organisation for Technical Approvals, 2005.

Feldmann, M., Kasper, R., \& Pilsl, M. (2008). Glass for Structural Applications - the development of the connection design. Proceedings of Challenging Glass, 557-569.

Haldimann, M., Luible, A., \& Overend, M. (2008). Structural use of glass (Vol. 10). IABSE.

Lees, D. E., \& Hutchinson, A. R. (1992). Mechanical characteristics of some cold-cured structural adhesives. International Journal of Adhesion and Adhesives, 12 (3), 197-205.

Maniatis, I. (2006). Numerical and Experimental Investigations on the Stress Distribution of Bolted Glass Connections under In-Plane Loads (Doctoral dissertation). Technische Universität München, Germany. 
Mocibob, D., \& Belis, J. (2010). Coupled experimental and numerical investigation of structural glass panels with small slenderness subjected to locally introduced axial compression. Engineering Structures, 32(3), 753-761.

Overend, M. (2005). Optimizing connections in structural glass. Proceedings of 2nd International conference on Glass in Buildings.

Overend, M., Jin, Q., \& Watson, J. (2011). The selection and performance of adhesives for a steel-glass connection. International Journal of Adhesion and Adhesives, 31(7), 587-597.

Overend, M., Nhamoinesu, S., \& Watson, J. (2012). Structural Performance of Bolted Connections and Adhesively Bonded Joints in Glass Structures. Journal of Structural Engineering, 139(12).

Santarsiero, M., Carvalho, P., Louter, C., \& Cruz, P. (2013). Experimental and numerical investigations of metal-to-glass embedded connections with thin stainless steel plate. Proceedings of COST Action TU0905, Mid-term Conference on Structural Glass.

Santarsiero, M., \& Louter, C., (2014). The mechanical behavior of SentryGlas ${ }^{\circledR}$ and TSSA laminated polymers in cured and uncured state in uniaxial tensile test. Proceedings of Challenging Glass, 4 \& COST TU0905 Final Conference.

Siebert, B. (2006). Anforderungen für ein Berechnungskonzept für die Bemessung punktgelagerter Verglasungen, Stahlbau, 75(8), 652-657.

Siebert, G., \& Herrmann, T. (2010). Glazing with countersunk point fittings. Proceedings of Challenging Glass, 3, 335-348.

SIMULIA (2011). Abaqus 6.11 Analysis User's Manual - Volume IV: Elements.

Sitte, S., Brasseur, M. J., Carbary, L. D., \& Wolf, A. T. (2011). Preliminary Evaluation of the Mechanical Properties and Durability of Transparent Structural Silicone Adhesive (TSSA) for Point Fixing in Glazing. Journal of ASTM International, 8(10), 1-27.

Vyzantiadou, M. A., \& Avdelas, A. V. (2004). Point fixed glazing systems: Technological and morphological aspects. Journal of Constructional Steel Research, 60(8), 1227-1240.

Weller, B., \& Tasche, S. (2005). Adhesive Fixing in Glass Construction. Proceedings of the 9th International Conference on Architectural and Automotive Glass (GPD), 267-270.

Yu, X. X., Crocombe, A. D., \& Richardson, G. (2001). Material modelling for rate-dependent adhesives. International journal of adhesion and adhesives, 21(3), 197-210. 